\title{
Intelligent Multiobjective Slip and Speed Ratio Control of a Novel Dual-Belt Continuously Variable Transmission for Automobiles
}

\author{
Zhengchao Xie, Pak Kin Wong, Yueqiao Chen, and Ka In Wong \\ Department of Electromechanical Engineering, University of Macau, Taipa, Macau \\ Correspondence should be addressed to Zhengchao Xie; zxie@umac.mo
}

Received 9 May 2014; Accepted 5 July 2014; Published 19 August 2014

Academic Editor: Qingsong Xu

Copyright (C) 2014 Zhengchao Xie et al. This is an open access article distributed under the Creative Commons Attribution License, which permits unrestricted use, distribution, and reproduction in any medium, provided the original work is properly cited.

\begin{abstract}
Van Doorne's continuously variable transmission (CVT) is the most popular CVT design for automotive transmission, but it is only applicable to low-power passenger cars because of its low torque capacity. To overcome this limitation of traditional singlebelt CVT, a novel dual-belt Van Doorne's CVT (DBVCVT) system, which is applicable to heavy-duty vehicles, has been previously proposed by the authors. This paper, based on the published analytical model and test rig of DBVCVT, further proposes an intelligent multiobjective fuzzy controller for slip and speed ratio control of DBVCVT. The controller aims to safely control the clamping forces of both the primary and the secondary pulleys in order to improve the transmission efficiency, achieve the accurate speed ratio, and avoid the belt slip under different engine loads and vehicle speeds. The slip, speed ratio, and transmission efficiency dynamics of DBVCVT are firstly analyzed and modeled in this paper. With the aid of a flexible objective function, the analytical model, and fuzzy logic, a Pareto rule base for fuzzy controller is developed for multiobjective DBVCVT control. Experimental results show that the proposed controller for slip and speed ratio regulation of DBVCVT is effective and performs well under different user-defined weights.
\end{abstract}

\section{Introduction}

Continuously variable transmission (CVT) is a type of automatic transmission that has been increasingly used in automotive applications. As compared to conventional automatic transmissions, CVT offers a wider range of transmission ratios, better shift quality, simpler mechanism, and lighter weight. It also has the advantages of infinite gear ratios, higher engine efficiency, and better fuel economy. Typically, Van Doorne's CVT with the single metal pushing V-belt is the most popular type of CVTs due to its good reliability and durability. However, the low torque capacity is one of the limitations of this popular single-belt Van Doorne's CVT (SBVCVT), making it only applicable to low-power passenger cars. Moreover, apart from the limited torque capacity, the modern SBVCVT also suffers from the belt slip problem. When the clamping force of the belt is too low, the belt on the CVT may slip and the power transmission becomes impossible. Thus, in normal SBVCVT control, the CVT is usually overclamped to prevent the metal belt from slipping. This excessive clamping force, on the other hand, results in additional friction losses in the system as extra mechanical load is applied to all parts of the variator. The excessive clamping force also reduces the life of the steel element of the CVT system since the extrusion force in the element is larger than needed for the transmission of engine power. The contact pressure between the V-belt and the pulleys is also higher than the minimum pressure required, which further increases the wear. Decreasing the clamping force is then a solution to improve the transmission efficiency, but as mentioned, too low clamping force will lead to large slip value, and the system will become unstable [1-3]. Besides, it is noted that if the clamping force is increased to avoid the slip, the speed ratio must be changed slightly. In fact, an accurate and fast control of the rate of change of speed ratio is a prerequisite for supplementing the shiftpoint control, which affects the vehicle fuel consumption and acceleration performance because a correct shift point 


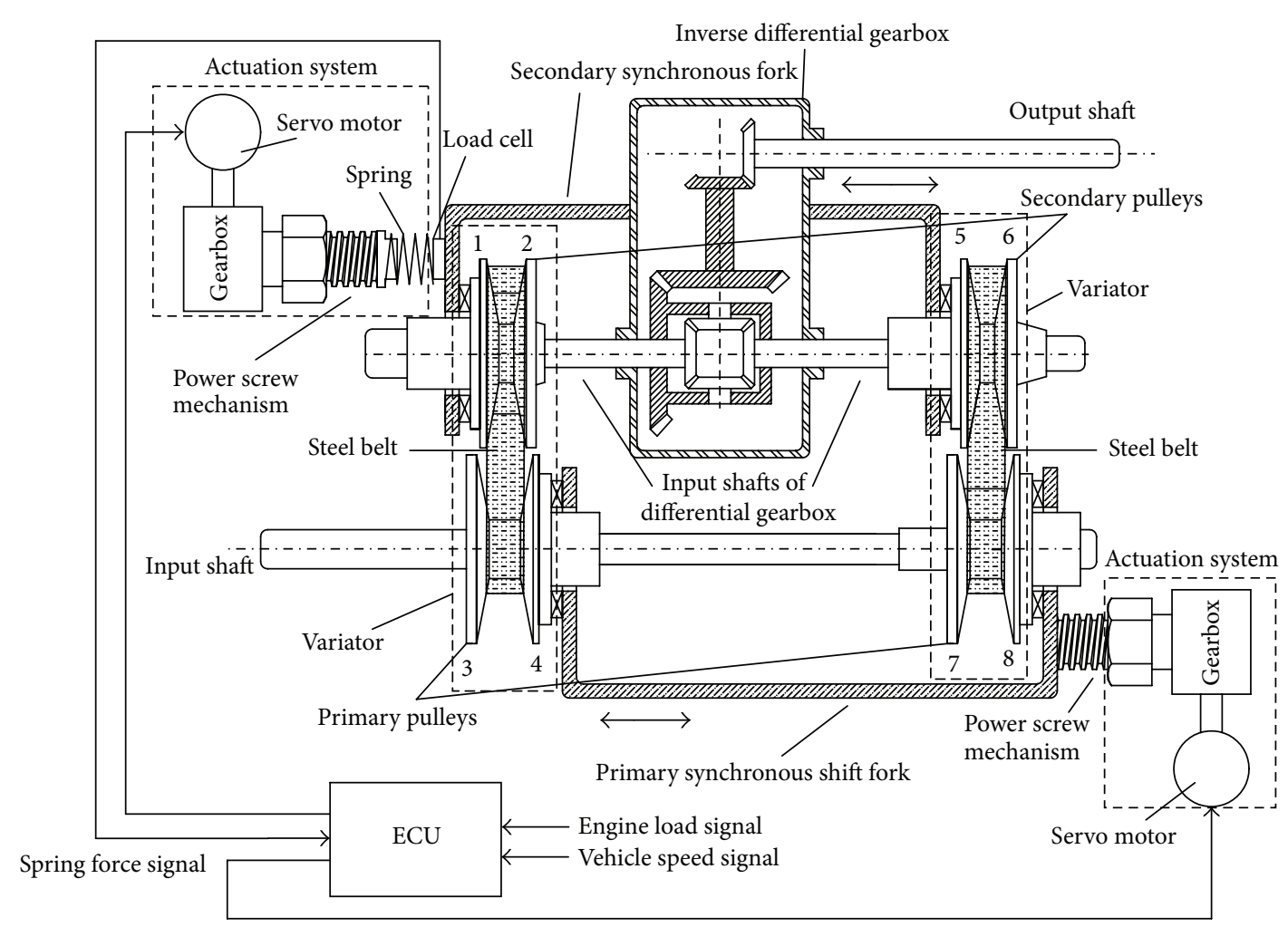

Figure 1: Schematic design of DBVCVT.

considers the powertrain and the vehicle characteristics. In order to maintain a steady-state speed ratio, an optimal pulley thrust is required. Hence, improving the performance of SBVCVT has recently attracted many researchers' attentions [1-4].

In a previous work of the authors [4], a novel parallel CVT system, namely, dual-belt Van Doorne's CVT (DBVCVT), was proposed to overcome some of the deficiencies of SBVCVT. As shown in Figure 1, the proposed DBVCVT design consists of two identical SBVCVT systems to increase the torque capacity and a synchronous mechanism to integrate the two SBVCVT systems. An analytical model has been developed for the DBVCVT and a test rig has been fabricated. It has already been verified in [4] that this novel DBVCVT can be implemented on heavy-duty vehicles and has significant improvement on the torque capacity. Nevertheless, the inadequate transmission efficiency due to the belt slip problem is still the major drawback of this novel DBVCVT system. Although the transmission efficiency can be improved by reducing the clamping force, it is at the risk of slip and the speed ratio may tend to change. To deal with the slip and speed ratio problem of CVT for the improvement of transmission efficiency, the slip and speed ratio control is necessary for the DBVCVT, but it has not been done in the previous work.

In the literature, there are several ways of controlling the belt slip and speed ratio. Bonsen et al. $[5,6]$ developed a robust gain-scheduling proportional-integral (PI) controller based on a linearized slip model to measure and control slip in a SBVCVT while minimizing clamping forces and preventing destructive belt slip. The gains were scheduled based on primary speed, speed ratio, and slip. Slip was used to determine whether the system undergone microslip or macroslip. The set point also varied with the ratio, since the maximum traction coefficient could be attained for different slip values depending on the ratio. However, the slip control system was designed for quasistatic ratio control, which does not hold in dynamic driving situations. Moreover, the selection of the control gains is also timeconsuming and engineer experience dependent. Saito and Lewis [7] developed a simulation technique for a SBVCVT with feedback thrust controllers. Multibody formalisms were used to model the belt, and a modified PI controller was used to adjust the pulley thrusts to obtain a desired speed ratio.

Setlur et al. [8] developed an adaptive nonlinear control algorithm for the asymptotic tracking of the desired wheel speed by ensuring that the SBVCVT speed ratio tracks a desired gear ratio profile. The CVT used in their model to capture the gear ratio dynamics was assumed as a purely firstorder integrator system.

Kim et al. [9] suggested a fuzzy logic-based speed ratio control algorithm for the SBVCVT system considering the on-off characteristics of the speed ratio control valve and the nonlinear characteristics of CVT dynamics. Their experimental results showed that a desired speed ratio could be achieved at steady state by fuzzy logic in spite of the fluctuating primary pressure. In addition, it was found that faster response and better robustness characteristics could be 
obtained by fuzzy logic control than a standard proportionalintegral-derivative (PID) control. Ryu et al. [1] developed a model-based control algorithm for the hydraulic pressurecontrolled CVT using the steady-state characteristics of the speed ratio control valve. In a hydraulic pressure-controlled CVT system, the desired speed ratio is obtained by controlling the primary actuator pressure. The authors proposed that linear control algorithms, such as PID type control, could be used for the pressure-control type CVT, whereas nonlinear or adaptive control logic should be implemented for the flow-control type CVT. Pesgens et al. [10] developed a new speed ratio controller for a SBVCVT with a hydraulic clamping system. Using the dynamic models of the variator and hydraulic power and compensator constraints, a set point feedforward and a linearizing feedback controller were implemented. The feedback controller was a PID controller with a conditional antiwindup protection. The total ratio controller guaranteed that at least one of the pressure set points was always minimal with respect to its constraints, while the other was raised above the minimum level to enable shifting. Rothenbühler [11] implemented a PI and a model reference adaptive control (MRAC) with a feedforward, of which two feedforwards were proposed: a simple feedforward (SFF) and a mapping feedforward (MFF). SFF only controlled the primary clamping force, while MFF considered that the needed clamping force was known for a certain slip reference, a certain speed ratio, and load factor.

In a nutshell, no research has studied the controller design for DBVCVT yet. Moreover, the existing literature shows that the development of the CVT control mainly focuses on either the slip control or the speed control. The slip control is designed to ensure the torque transmission and improve the efficiency. A reasonable slip control also extends the service life of the CVT. The speed ratio control is developed to minimize the error between the actual speed ratio and the target speed ratio. Although many scholars made many efforts on these two control targets and achieved good results, most of them still regarded the slip control and the speed ratio control as two separated systems. However, in practice, adjusting the clamping force to avoid the slip will result in changing the speed ratio concurrently, so the control of slip and speed ratio should be considered at the same time. Some scholars proposed the decoupling control of the slip and speed ratio control [11, 12], but this control concept is also inherently a kind of independent control. Moreover, this kind of control is very sensitive to the changes in system parameters. In fact, inaccurate system parameters and even some variation of system parameters in the control process can result in the failure of the decoupling control [13]. In short, the existing literature reveals that there is no CVT controller viewing the slip control and the speed ratio control as a multiobjective optimal control problem. Thus, one of originalities of this paper is to study the slip control and speed ratio control together. For addressing this multiobjective problem with multi-input and multioutput and the highly nonlinearity of the proposed DBVCVT system, this paper chooses the fuzzy control strategy to deal with this multiobjective optimal control problem. The fuzzy controller is usually based on experts' knowledge and experience. For those control plants with complicated dynamic behavior and high nonlinearity, like the DBVCVT system, the strong robustness of fuzzy controller is suitable for complicated dynamic systems and is able to adapt to the impact of external disturbance [14]. However, the problem of typical fuzzy controller for multiobjective optimal control is the rulemaking. In fact, it is very difficult to obtain optimal control rules. To solve this problem, this paper introduces the concept of Pareto rule base, which is developed based on an objective function, the analytical model of the DBVCVT system, and fuzzy logic. The Pareto rule base consists of a set of optimal fuzzy control rules which are selected from all combinations of fuzzy rules in the problem domains based on Pareto selection algorithm (Pareto strategy). With the Pareto rule base, the multiobjective fuzzy controller can rapidly select satisfactory control signals according to different operating conditions $[15,16]$. The main objective of the proposed fuzzy controller for the DBVCVT is to automatically determine the optimal control action in order to balance the goals of high efficiency, accurate speed ratio, and low belt slip.

The organization of this paper is as follows. The formulation of multiobjective optimal control is proposed in Section 2. An analytical model of DBVCVT in terms of slip, speed ratio, and transmission efficiency dynamics is derived in Section 3. The model is used for determining system response in Pareto selection algorithm. The details of the controller design are presented and the implementation of the controller and some experimental results are provided in Section 4. Conclusions and further development are given in Section 5.

\section{General Formula of Multiobjective Optimal Control Problem}

This section mainly introduces the Pareto strategy for multiobjective optimal control problem. More details for this strategy can be found in [14-18].

\subsection{Basic Concepts and Definitions}

Definition 1 (control algorithm and system). A mapping is defined as a control algorithm:

$$
\begin{aligned}
& f: I \times X \longrightarrow U, \\
& \forall(t, x) \in I \times X, \quad(t, x) \mid \longrightarrow u=f(t, x),
\end{aligned}
$$

where $I \subseteq[0,+\infty)$ is a finite or infinite interval, $X$ is the domain of system state, and $U$ is the domain of system control variable. Obviously, the control algorithm decides the system response process over the time $t$, which can be expressed as a curve over the time $t$, and this is defined as the tracking curve of system state generated by the control algorithm $f$ [17].

Definition 2 (function of system response process). The controlled plant is considered as $P . S$ is defined as a system with $q$ inputs and $r$ outputs. $\zeta$ is defined as the disturbance with the domain $\Xi . u$ is defined as the system control variable with the domain $U$. This paper defines $u_{0}, u_{1}, \ldots, u_{n}$ as 
the step sequence of $u$ with the initial value $u_{0}$, which means $u$ jumps from $u=u_{k-1}$ to $u=u_{k}$ at the time $t_{k}$, $k=1,2, \ldots, n$. Moreover, the system response process of $S$ with the initial value $S\left(t_{0}, u_{0}\right)$ can be expressed by a response function $S\left(t, u, \zeta \mid u_{0}, u_{1}, \ldots, u_{n}\right)$ with the time variable $t$, the system control variable $u$, and the disturbance $\zeta$. In most cases, the disturbance can be considered as some noises of the system input, so the response function can be written by $S\left(t, u \mid u_{0}, u_{1}, \ldots, u_{n}\right)[14,17]$.

2.2. Formulation of Multiobjective Optimal Control Problem. By observing the general case on the multiobjective control problem, it can be concluded that the satisfying degree to each objective is dependent on the feature of response function $S\left(t, u \mid u_{0}, u_{1}, \ldots, u_{n}\right)$ [17]. Since all evaluations to objectives should be finished in a finite time, this paper considers a general form for the multiobjective control problem, in which the control sequence is finite.

In fact, there is no best solution to the problem itself in this study because the objectives of high efficiency, accurate speed ratio, and low belt slip are conflicting to each other. Therefore, seeking an "optimal solution" instead of "best solution" becomes a strategy to solve this multiobjective control problem. The key of this control is to design a control algorithm; for all initial states, the control algorithm can generate a sequence to control the corresponding response function and then achieve all targets in the sense of compromise. It can be noted that all targets change along with the time, so the general objective function vector can be defined as

$$
\begin{aligned}
\operatorname{Min} g( & \left.\left(t, u \mid u_{0}, u_{1}, \ldots, u_{l}\right)\right) \\
= & \left(g_{1}\left(S\left(t, u \mid u_{0}, u_{1}, \ldots, u_{l}\right)\right),\right. \\
& g_{2}\left(S\left(t, u \mid u_{0}, u_{1}, \ldots, u_{l}\right)\right), \ldots, \\
& \left.g_{n}\left(S\left(t, u \mid u_{0}, u_{1}, \ldots, u_{l}\right)\right)\right)
\end{aligned}
$$

subject to

$$
\begin{gathered}
h_{1}\left(S\left(t, u \mid u_{0}, u_{1}, \ldots, u_{l}\right)\right) \geq 0, \\
\vdots \\
h_{p}\left(S\left(t, u \mid u_{0}, u_{1}, \ldots, u_{l}\right)\right) \geq 0, \\
h_{p+1}\left(S\left(t, u \mid u_{0}, u_{1}, \ldots, u_{l}\right)\right)=0, \\
\vdots \\
h_{p+q}\left(S\left(t, u \mid u_{0}, u_{1}, \ldots, u_{l}\right)\right)=0,
\end{gathered}
$$

where $g_{0}, g_{1}, \ldots, g_{n}$ are objectives and $h_{k}, k=1,2, \ldots, p+q$ are constraints.
$Q$ is denoted as the feasible region of system control variable $u$, which is limited by constraints, and $\lambda$ is defined as a compromising operator:

$$
\begin{aligned}
& \lambda: R^{n} \longrightarrow R^{l}, \\
& \forall x \in\left(x_{1}, x_{2}, \ldots, x_{n}\right) \in R^{n}, \quad x \mid \longrightarrow \lambda(x) \in R^{l},
\end{aligned}
$$

where $x=\left(x_{1}, x_{2}, \ldots, x_{n}\right)$ is defined as the system state.

Therefore, the multiobjective optimal control problem can be converted to find the control input sequence $\left(v_{0}, t_{1}\right),\left(v_{1}, t_{2}\right), \ldots,\left(v_{l}, t_{1+1}\right)$, such that

$$
\begin{aligned}
& \lambda\left(g\left(S\left(t, v \mid v_{0}, v_{1}, \ldots, v_{l}\right)\right)\right) \\
& \quad=\min _{u_{1}, u_{2}, \ldots, u_{l} \in Q} \lambda\left(g\left(S\left(t, u \mid u_{0}, u_{1}, \ldots, u_{l}\right)\right)\right),
\end{aligned}
$$

where $v_{k} \in Q, k=1,2, \ldots, l$.

The general formula of multiobjective control problem can be shown by

$$
\begin{array}{ll}
\min & f_{1}\left(x_{1}, x_{2}, \ldots, x_{n}\right) \\
& \vdots \\
& \min _{r}\left(x_{1}, x_{2}, \ldots, x_{n}\right) \\
\max & f_{r+1}\left(x_{1}, x_{2}, \ldots, x_{n}\right) \\
& \vdots \\
& f_{m}\left(x_{1}, x_{2}, \ldots, x_{n}\right) \\
\max & \\
\text { s.t. } & g_{j}\left(x_{1}, x_{2}, \ldots, x_{n}\right) \geq 0, \quad j=1,2, \ldots, p \\
& h_{k}\left(x_{1}, x_{2}, \ldots, x_{n}\right)=0, \quad k=1,2, \ldots, q,
\end{array}
$$

where the functions $f_{1}\left(x_{1}, x_{2}, \ldots, x_{n}\right), f_{2}\left(x_{1}, x_{2}, \ldots, x_{n}\right), \ldots$, $f_{r}\left(x_{1}, x_{2}, \ldots, x_{n}\right)$ need to be minimized and the functions $f_{r+1}\left(x_{1}, x_{2}, \ldots, x_{n}\right), \quad f_{r+2}\left(x_{1}, x_{2}, \ldots, x_{n}\right), \ldots, f_{m}\left(x_{1}, x_{2}, \ldots\right.$, $x_{n}$ ) need to be maximized simultaneously. There are some commonly used compromising operators [14].

The weights are shown by

$$
\begin{array}{r}
\lambda\left(f_{1}, f_{2}, \ldots, f_{n}\right)=w_{1} f_{1} \wedge w_{2} f_{2} \wedge \cdots \wedge w_{n} f_{n} \\
\left(w_{k} \geq 0, k=1,2, \ldots, n, \sum_{k=1}^{n} w_{k}=1\right),
\end{array}
$$

where $w_{k}$ is the weight.

2.3. Weight Selection and Normalization. Since this paper aims to optimize the performance of DBVCVT, the control has to assure that each target can reach the optimal value. In other words, each target (slip, speed ratio, and transmission efficiency) is not necessary to reach its best value but approach it as much as possible. However, due to conflicts among various targets, especially that increasing the satisfying degree of a particular target can lead satisfying 
degrees of other targets to decrease, it is important to assign appropriate weights to these targets so as to obtain an optimal solution. The selection of weight of each target is an important issue to directly determine the control action. Currently, there are many methods of determining weights, which can be broadly divided into two categories $[14,17]$. The first one is the subjective assignment method in which various experts and decision makers evaluate various factors based on their subjective judgments or intuitions. The other category is the objective assignment method, which uses the objective information or statistical data analysis to determine weights, such as principal component analysis. As an illustration, this research considers the subjective weight selection [17]. In general cases, the weight of the objective $O_{i}(i=1,2, \ldots, m)$ is considered as $w_{i}\left(\sum_{i=1}^{m} w_{i}=1\right)$.

Apart from the weight selection, normalization also plays an important role to the system performance. In this study, normalization function $N(\cdot)$ is used to transform the objective component value to the range $[0,1]$ so as to ensure each component has the same contribution to the fitness function. The general form of the normalization function is given by

$$
x_{t}^{*}=\frac{x_{t}-x_{\min }}{x_{\max }-x_{\min }},
$$

where $x_{t}^{*}$ is the normalized performance index and $x_{\max }$ and $x_{\min }$ are the upper limit and lower limit of the performance index before normalization.

\subsection{Pareto Rule and Pareto Rule Base}

Definition 3 (rule base). $X=X_{0} \times X_{1} \times \cdots \times X_{n}$ is defined as the domain of system state, and $U$ is the domain of system control variable. The $j$ th control rule can be defined as follows:

$$
R_{j}: \text { if } x_{i} \text { is } A_{j 1}, x_{2} \text { is } A_{j 2}, \ldots, x_{n} \text { is } A_{j n} \text {, then } u \text { is } C_{j} .
$$

Here, $A_{j k} \in F^{*}\left(X_{k}\right), C_{j} \in F^{*}(U), j=1,2, \ldots, q, k=$ $l, l+1, \ldots, n . F^{*}(X)$ is defined as the set of all fuzzy points in the domain $X$. Moreover, $R_{j}$ can be written by $\left(A_{j}, C_{j}\right)$, where

$$
A_{j}=\prod_{k=1}^{n} A_{j k}=A_{j 1} \times A_{j 2} \times \cdots \times A_{j n},
$$

or

$$
\begin{aligned}
& \forall x \in\left(x_{1}, x_{2}, \ldots, x_{n}\right) \in X \\
& \begin{aligned}
A_{j}(x) & =\bigwedge_{k=1}^{n} A_{j k}\left(x_{k}\right) \\
& =A_{j 1}\left(x_{1}\right) \wedge A_{j 2}\left(x_{2}\right) \wedge \cdots \wedge A_{j n}\left(x_{n}\right) .
\end{aligned}
\end{aligned}
$$

Then, $R=\left(R_{1}, R_{2}, \ldots, R_{q}\right)$ can be considered as a rule base in $P$. When $\forall x=\left(x_{1}, x_{2}, \ldots, x_{n}\right) \in X, \exists R_{j} \in R$ and $A_{j}(x) \neq 0, R_{j}$ can be considered as a response rule at the point of $x . R$ is equivalent to the complete fuzzy rule set; this completeness indicates that there exists a rule at any point in the input space; the membership value of the "if" part of the rule at this point is nonzero [18].

The base point set of the input domain can be established too. First, the whole domain of the system input is divided into some divisions according to certain rules, and a membership function is defined in each division. Here, the membership function value shows the relative importance of a point in this division. Furthermore, this value can be 1 at a certain point in this division; then this point can be considered as a base point in the division. Similarly, other base points can be found in other divisions, and these base points constitute a base point set of the whole domain. The purpose of the base point set of the input domain is to change a continuous input domain into some discrete finite regions, then the experts can consider separately for each region [18]. However, the base point set of the output domain cannot be constructed in accordance with the above method, because each control output should be based on the actual need to determine but not determined by the subjective judgment.

Definition 4 (extended rule). $X=X_{1} \times X_{2} \times \cdots \times X_{n}$ is defined as the domain of system state and $U=U_{1} \times U_{2} \times \cdots \times$ $U_{m}$ is defined as the domain of system control variable. The extended rule can be defined as

$$
R: \text { if } x(t) \text { is } A \text {, then } u(t) \text { is } W \text {, so that } x(t+T) \text { is } B \text {. }
$$

There are two meanings in this extended rule:

(1) $\forall x \in \operatorname{supp} A, \forall u \in \operatorname{supp} W$; the result is $x(t+T)=$ $P(x, u, T) \in \operatorname{supp} B ;$

(2) $\forall b \in \operatorname{supp} B, \exists x \in \operatorname{supp} A, \exists u \in \operatorname{supp} W$, so there is $p(x, u, T)=b$,

where $0<T_{0} \leq \forall T \leq T_{1}, A \in F^{*}(X), W \in F^{*}(U)$, and $B \in$ $F^{*}(X) . B$ can be considered as the result state of rule $R . T_{0}$ and $T_{1}$ are defined as the minimum and maximum acting time of rule $R$, respectively. For convenience, $T=\left(T_{0}+T_{1}\right) / 2$ is defined as the acting time of rule $R$. The extended rule can be written by $R=(A, W, T ; B)[17]$.

Definition 5 (supporting degree of a rule to an objective). $R=(A, W, T ; B)$ is defined as an extended rule in $P, a$ is the input base point of $R$, and $v$ is the output base point of $R$. $g\left(S\left(t, u \mid u_{0}, u_{1}, \ldots, u_{n}\right)\right)$ is defined as an objective function of the system. Considering the system response function $S(t, u)$ $u_{0}, u_{1}$ ) with the initial state $a$ and the control input $u_{1}=v$, then the favoring degree $g\left(S\left(t, u \mid u_{0}, u_{1}\right)\right)$ can be generated by the system response function $S\left(t, u \mid u_{0}, u_{1}\right)$ with respect to the objective $g$ within the time interval $t \in\left[t_{1}, t_{1}+T\right]$, where $T$ is the control cycle. It can be noted that this favoring degree is considered as the supporting degree of rule $R$ at the base point $a$ with respect to the objective $g$, which can be expressed by $g(R)$. The supporting degree of a rule to an objective can be used to make an order of the rules with the same response area, so that the most suitable rule can be selected among them in terms of the supporting degree [14].

Definition 6 (Pareto rule). The Pareto rule refers that increasing the satisfying degree of one objective by changing 
the output of this rule can lead satisfying degrees of other objectives to decrease [18]. $R=Q_{1} \cup Q_{2} \cup \cdots \cup Q_{q}$ is defined as a rule base of the system $P$, where $Q_{k}=$ $\left\{R_{k 1}, R_{k 2}, \ldots, R_{k m}\right\} ; k=1,2, \ldots, q$ has the same response area and input base point. $g\left(S\left(t, u \mid u_{0}, u_{1}, \ldots, u_{n}\right)\right)$ can be defined as the objective vector of the system $P$ and $\lambda\left(x_{1}, x_{2}, \ldots, x_{n}\right)$ is a compromising operator. The rule $R_{k j}$ is defined as the optimal Pareto rule with respect to the rule set $Q_{k}$ and can be expressed by

$$
g\left(R_{k j}\right)=\bigvee_{i=1}^{n} \lambda\left(g_{1}\left(R_{k j}\right), g_{2}\left(R_{k j}\right), \ldots, g_{n}\left(R_{k j}\right)\right),
$$

where

$$
\begin{aligned}
g(S(t, u \mid & \left.\left.u_{0}, u_{1}, \ldots, u_{n}\right)\right) \\
= & \left(g_{1}\left(S\left(t, u \mid u_{0}, u_{1}, \ldots, u_{n}\right)\right)\right. \\
& g_{2}\left(S\left(t, u \mid u_{0}, u_{1}, \ldots, u_{n}\right)\right), \ldots, \\
& \left.g_{n}\left(S\left(t, u \mid u_{0}, u_{1}, \ldots, u_{n}\right)\right)\right) .
\end{aligned}
$$

Therefore, the Pareto rule base is regarded as every rule in the rule base is an optimal Pareto rule [18].

2.5. Development of Pareto Rule Base. This section introduces a comprehensive approach for constructing a Pareto rule base [18]. The goal of the system control is to make the overall state of the control plant change along with the preset track. Moreover, some of the indicators of the controlled object in this process should be limited in order to meet the requirements of the system. It is assumed that the system state variables are $X$ and $Y$ and the system input variables are $U$ and $V$. The system response function is defined as $S(t, u, v \mid$ $(u, v))$. There are some steps to build the Pareto rule base.

Step 1. Select base point sets of domains of state and input variables.

This paper considers that certain parameters of membership function of the fuzzy control system are fixed to optimize the rules and constructs base point sets of state and input variables through the appropriate division. Therefore, the base point set of system state variable $X$ is defined as

$$
X=\left\{a_{1}, a_{2}, \ldots, a_{p}\right\}, \quad a_{1}<\cdots<a_{p} .
$$

The base point set of system state variable $Y$ is defined as

$$
Y=\left\{b_{1}, b_{2}, \ldots, b_{q}\right\}, \quad b_{1}<\cdots<b_{q} .
$$

The base point set of system input variable $U$ is defined as

$$
U=\left\{u_{1}, u_{2}, \ldots, u_{m}\right\}, \quad u_{1}<\cdots<u_{m} .
$$

The base point set of system input variable $V$ is defined as

$$
V=\left\{v_{1}, v_{2}, \ldots, v_{n}\right\}, \quad v_{1}<\cdots<v_{n} .
$$

Step 2. Identify all possible states of the system after the time interval $T$.
The base point group of system state variables is defined as $w_{i j}(i=1,2, \ldots, p, j=1,2, \ldots, q)$, the corresponding base point group for state input variables is $\left(u_{k}, v_{l}\right)$, and the corresponding rule at these base points is $R_{i j k l}$. All these rules with the initial system state $w_{i j}$ constitute a rule set $\left\{R_{k l}\right\}$. The composition of all rules with the initial system state $w_{i j}$ can generate a new system state $w_{i j k l}(k=$ $1,2, \ldots, m, l=1,2, \ldots, n)$ after a time interval $T$. The corresponding response result set is expressed by

$$
\begin{aligned}
& \left\{S_{i j}\left(t, u_{1}, v_{1}\right), S_{i j}\left(t, u_{2}, v_{1}\right), \ldots,\right. \\
& \left.\quad S_{i j}\left(t, u_{k}, v_{1}\right), S_{i j}\left(t, u_{1}, v_{2}\right), \ldots, S_{i j}\left(t, u_{k}, v_{l}\right)\right\},
\end{aligned}
$$

where $k=1,2, \ldots, m, l=1,2, \ldots, n$.

Step 3. As for the above response result $\left\{S_{i j}\left(t, u_{i}, v_{j}\right)\right\}, i=$ $1,2, \ldots, m, j=1,2, \ldots, n$, this study calculates the satisfying degree of an objective under constraints and then obtains the optimal response result and the corresponding optimal rule, which are associated with a given initial system state.

Step 4. $\forall a_{k} \in X$; a triangular fuzzy number of $X$ can be defined by

$$
A_{k}(x)=\operatorname{cut}\left[\frac{\left(x-a_{k}\right)}{\left(a_{k}-a_{k-1}\right)}\right] \vee\left[\frac{\left(a_{k+1}-x\right)}{\left(a_{k+1}-a_{k}\right)}\right],
$$

where $k=1,2, \ldots, p$. The definition of "cut" function with respect to $X$ is expressed by

$$
\operatorname{cut}(x)= \begin{cases}x & x \in[0,1] \\ 0 & x \notin[0,1]\end{cases}
$$

So, $X$ is divided into many fuzzy divisions by $A_{k}$. The set of fuzzy numbers $\Xi$ with respect to $X$ can be defined as

$$
\Xi_{X}=\left\{A_{1}, A_{2}, \ldots, A_{p}\right\} .
$$

Similarly, the set of fuzzy numbers $\Xi$ with respect to $Y$ can be defined as

$$
\Xi_{Y}=\left\{B_{1}, B_{2}, \ldots, B_{q}\right\} .
$$

The set of fuzzy numbers $\Xi$ with respect to $U$ can be defined as

$$
\Xi_{U}=\left\{U_{1}, U_{2}, \ldots, U_{m}\right\} .
$$

The set of fuzzy numbers $\Xi$ with respect to $V$ can be defined as

$$
\Xi_{V}=\left\{V_{1}, V_{2}, \ldots, V_{n}\right\} .
$$

According to Step 3, the optimal response result with the initial state $w_{i j}$ corresponds to the base point group $\left(u_{k}, v_{l}\right)$. Then, the optimal rule based on the fuzzy numbers of these base points can be defined as follows:

$$
R_{i j} \text { : if } X \text { is } A_{i} \text { and } Y \text { is } B_{j} \text {, then } U \text { is } U_{k}, V \text { is } V_{l} \text {. }
$$

This means $R=\left\{r_{i j} \mid i=1,2, \ldots, p, j=1,2, \ldots, q\right\}$ can be considered as the comprehensive Pareto rule base. The method of this paper is to search for the optimal rule based on fixed membership function parameters. 


\section{Analytical Model of DBVCVT Slip, Speed Ratio, and Efficiency Dynamics}

Currently, almost all fuzzy control systems use the "ifthen" rule. The control rules and membership functions are usually dependent on experts' knowledge or experience. The main idea of the proposed fuzzy control system is to select suitable fuzzy control rule from optimal control rule base in order to make the control perform satisfactorily. This paper adopts fuzzy logic theory, an objective function, and an exact analytical model of DBVCVT of slip, speed ratio, and efficiency dynamics, to derive the optimal control rules.

In the previous work [4], an analytical model of DBVCVT has been developed. The comparison in [4] showed that the simulation results of the analytical model are in good agreement with the experimental results. Hence, it can act as an effective and accurate tool to predict the transmission process for the slip and speed ratio control (i.e., system response). To obtain the power transmission efficiency, the previous modeling work has considered many kinds of power losses of DBVCVT except slip loss. However, when the slip happens, the slip loss also occurs. Although the slip loss is generally much smaller than other losses in a V-belt variator, it cannot be neglected. In fact, the slip loss tends to increase when the clamping force is reduced.

With the consideration of slip, the geometric ratio can be defined as

$$
i_{g}=\frac{r_{s}}{r_{p}}
$$

The speed ratio can be defined as

$$
i=\frac{\omega_{p}}{\omega_{s}} .
$$

The slip ratio can be defined as

$$
\varepsilon=1-\frac{\omega_{s}}{\omega_{p}} i_{g} .
$$

The input and output speeds can be, respectively, measured by a speed sensor which is a 60-toothed magnetic pickup; then the speed ratio can be obtained from (25). From (26), it is noted that the key to measure the slip is to determine the geometric ratio $i_{g}$. In this paper, by measuring the axial displacement of the primary pulley, the corresponding geometric ratio $i_{g}$ can be calculated. This is accomplished by installing a linear variable differential transformer (LVDT) to measure the axial position of the primary pulley.

When $i_{g, \text { min }}=0.44$, the working radius of primary pulley can be shown as

$$
r_{p}=r_{p 1}
$$

The corresponding working radius of secondary pulley can be shown as

$$
r_{s}=i_{g, \min } \cdot r_{p 1} \cdot
$$

When $i_{g \text {, max }}=2.25$, the measured maximum of axial moving displacement of the primary pulley $\Delta r_{p \text {, max }}$ is 14.56 $\mathrm{mm}$, so the working radius of primary pulley can be regarded as

$$
r_{p}=r_{p 2}=r_{p 1}+\frac{\Delta r_{p, \max }}{2 \tan \theta_{p}}
$$

The corresponding working radius of secondary pulley can be considered as

$$
r_{s}=r_{s 2}=i_{g, \max } \cdot r_{p 2}=i_{g, \max } \cdot\left(r_{p 1}+\frac{\Delta r_{p, \max }}{2 \tan \theta_{p}}\right) .
$$

The working length of steel belt can be calculated with

$$
L=r_{p}(\pi+2 \alpha)+r_{s}(\pi-2 \alpha)+2 a \cos \alpha .
$$

Based on (27) (31), the working radius of primary pulley $r_{p 1}$ and working length of steel belt $L$ can be calculated.

Then, when the geometric ratio $i_{g}$ needs to be determined, the working radius of primary pulley can be defined as

$$
r_{p}=r_{p 1}+\frac{\Delta r_{p}}{2 \tan \theta_{p}}
$$

The corresponding working radius of secondary pulley $r_{s}$ can be calculated by (31). With reference to (24), the geometric ratio $i_{g}$ can be obtained. The slip loss can be defined as

$$
P_{\text {slip }}=\omega_{p}-\frac{\omega_{s} r_{s}}{r_{p}}
$$

With reference to the design of DBVCVT and the above consideration of slip loss, the transmission efficiency $\eta$ based on the input power from the primary pulleys to the secondary pulleys in [4] is redefined as

$$
\begin{aligned}
\eta= & \frac{\eta_{d} \cdot\left[2 T_{i}-9549 \cdot\left(P_{1}+P_{2}+P_{3}+P_{4}+P_{5}+P_{6}\right)\right]}{2 T_{i}} \\
& \times\left(1-\frac{P_{\text {slip }}}{\omega_{p}}\right) \times 100 \% .
\end{aligned}
$$

The power loss due to the radial friction between the steel element and the pulley can be given by the following:

$$
\begin{aligned}
P_{1}= & \omega_{p}\left[F_{p}\left(\beta_{p}\right) r_{p i}-F_{p}(0) r_{p o}\right] \\
& +\omega_{s}\left[F_{s}(0) r_{s o}-F_{s}\left(\beta_{s}\right) r_{s i}\right] \cdot n .
\end{aligned}
$$

The power loss due to the tangential friction between the steel element and the pulley can be given:

$$
P_{2}=0.07 \varepsilon v_{p}\left(\frac{Q_{p}}{\cos \left(\theta_{p} / 2\right)}+\frac{Q_{s}}{\cos \left(\theta_{s} / 2\right)}\right) \cdot n .
$$


The power loss due to the friction between inner layer of steel ring and contact surface of steel element can be defined as

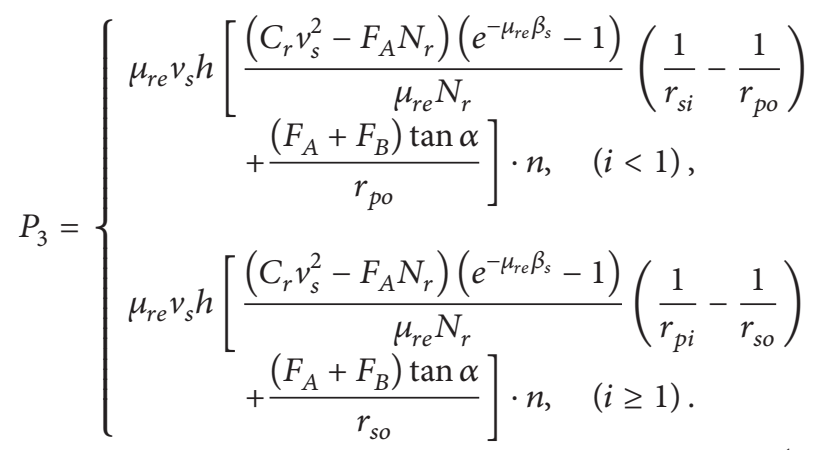

The kinetic energy loss of the steel element is defined as

$$
P_{4}=\left\{\begin{array}{l}
\frac{1}{2} m_{e} V_{e}^{3}\left(\frac{2 h \cdot r_{p o}+h^{2}}{h_{e} r_{p o}^{2}}+\frac{2 h \cdot r_{s i}+h^{2}}{h_{e} r_{s i}^{2}}\right) \cdot n, \\
\frac{1}{2} m_{e} V_{e}^{3}\left(\frac{2 h \cdot r_{p i}+h^{2}}{h_{e} r_{p i}^{2}}+\frac{2 h \cdot r_{s o}+h^{2}}{h_{e} r_{s o}^{2}}\right) \cdot n, \\
(i \geq 1) .
\end{array}\right.
$$

The power loss due to speed-dependent bearing frictional torque of the input shaft is given as follows:

$$
P_{5}= \begin{cases}\frac{10^{-10} \cdot d_{b}^{3} n_{i}^{5 / 3} n \cdot f_{b} v_{b}^{2 / 3}}{9549}, & v_{b} \cdot n_{i} \geq 2000 \\ \frac{160 \cdot 10^{-10} \cdot d_{b}^{3} f_{b} n \cdot n_{i}}{9549}, & v_{b} \cdot n_{i}<2000 .\end{cases}
$$

The power loss due to speed-dependent bearing frictional torque of the output shaft is also given:

$$
P_{6}= \begin{cases}\frac{10^{-10} \cdot d_{b}^{3} n_{o}{ }^{5 / 3} n \cdot f_{b} v_{b}^{2 / 3}}{9549}, & v_{b} \cdot n_{o} \geq 2000, \\ \frac{160 \cdot 10^{-10} \cdot d_{b}^{3} f_{b} n \cdot n_{o}}{9549}, & v_{b} \cdot n_{o}<2000 .\end{cases}
$$

In (39) and (40), $n_{i}$ and $n_{o}$ are, respectively, the input speed of the primary pulley and the output speed of the secondary pulley in revolutions per minute (RPM).

Lastly, the transmission efficiency of the inverse differential gearbox in Figure 1 is considered. In this study, the transmission efficiency of the inverse differential gear $\eta_{d}$ is selected as 0.9 [19].
Moreover, the required axial clamping force of primary pulley under high transmission ratio $(i<1)$ can be obtained as follows:

$$
\begin{aligned}
Q_{p}=-\frac{1}{\mu_{p}} C_{p}\left(E_{A}-F_{A}+\right. & \left.C_{r} V_{r p}^{2}+C_{e} V_{e p}^{2}\right) \\
\cdot\left(e^{\mu_{p} \beta_{0 p}}-1\right)+C_{p}[ & \frac{1}{-\mu_{r e}}\left(F_{A}-C_{r} V_{r p}^{2}\right) \\
& \cdot\left(e^{-\mu_{r e} \beta_{p}}-e^{-\mu_{r e} \beta_{0 p}}\right) \\
& \left.-C_{e} V_{e p}^{2}\left(\beta_{p}-\beta_{0 p}\right)\right],
\end{aligned}
$$

where

$$
C_{p}=\frac{\cos \left(\theta_{p} / 2\right)-\mu_{e p} \cos \gamma \sin \left(\theta_{p} / 2\right)}{2\left(\sin \left(\theta_{p} / 2\right)+\mu_{e p} \cos \gamma \cos \left(\theta_{p} / 2\right)\right)} .
$$

The required axial clamping force of secondary pulley under high transmission ratio $(i<1)$ can be obtained as follows:

$$
\begin{aligned}
Q_{s}=-C_{s} & {\left[\frac{1}{\mu_{r e}}\left(F_{A}-C_{r} V_{r s}^{2}\right)\left(e^{\mu_{r e} \beta_{0 s}}-1\right)\right.} \\
& \left.-E_{A} \beta_{0 s}-C_{e} V_{e s}^{2} \beta_{0 s}\right] \\
+ & \frac{1}{\mu_{s}} C_{s}\left(e^{\mu_{s} \beta_{s}}-e^{\mu_{s} \beta_{0 s}}\right) \\
& \cdot\left(E_{A}-F_{A}+C_{r} V_{r s}^{2}+C_{e} V_{e s}^{2}\right),
\end{aligned}
$$

where

$$
C_{s}=\frac{\cos \left(\theta_{\mathrm{s}} / 2\right)-\mu_{e p} \cos \gamma \sin \left(\theta_{\mathrm{s}} / 2\right)}{2\left(\sin \left(\theta_{\mathrm{s}} / 2\right)+\mu_{e p} \cos \gamma \cos \left(\theta_{\mathrm{s}} / 2\right)\right)}
$$

The required axial clamping force of primary pulley under low transmission ratio $(i \geq 1)$ can be obtained as follows:

$$
\begin{aligned}
& Q_{p}=-C_{p}\{ \frac{2}{\mu_{r e}-\mu_{p}}\left(F_{A}-C_{r} V_{r p}^{2}\right)\left(e^{\mu_{r e} \beta_{0 p}}-1\right) \\
&-\frac{1}{\mu_{p}}\left(e^{\mu_{p} \beta_{0 p}}-1\right) \\
&\left.\times\left[\frac{\mu_{r e}+\mu_{p}}{\mu_{r e}-\mu_{p}}\left(F_{A}-C_{r} V_{r p}^{2}\right)+E_{A}+C_{e} V_{e p}^{2}\right]\right\} \\
&-C_{p}\left[\frac{1}{\mu_{r e}}\left(F_{A}-C_{r} V_{r p}^{2}\right)\left(e^{\mu_{r e} \beta_{p}}-e^{\mu_{r e} \beta_{0 p}}\right)\right. \\
&\left.\quad-C_{e} V_{e p}^{2}\left(\beta_{p}-\beta_{0 p}\right)\right],
\end{aligned}
$$




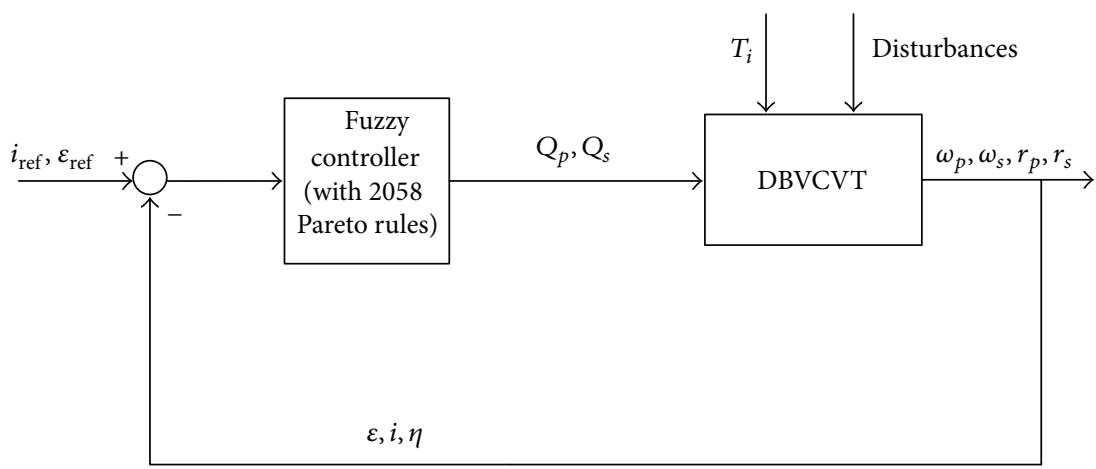

FIGURE 2: Proposed multiobjective speed ratio, slip, and transmission efficiency control for DBVCVT.

where

$$
C_{p}=\frac{\cos \left(\theta_{p} / 2\right)-\mu_{e p} \cos \gamma \sin \left(\theta_{p} / 2\right)}{2\left(\sin \left(\theta_{p} / 2\right)+\mu_{e p} \cos \gamma \cos \left(\theta_{p} / 2\right)\right)} .
$$

The required axial clamping force of secondary pulley under low transmission ratio $(i \geq 1)$ can be obtained as follows:

$$
\begin{aligned}
Q_{s}=C_{s}\left[\frac{1}{\mu_{r e}}\left(F_{A}-C_{r} V_{r s}^{2}\right)\left(e^{\mu_{r e} \beta_{0 s}}-1\right)-E_{A} \beta_{0 s}-C_{e} V_{e s}^{2} \beta_{0 s}\right] \\
+C_{s}\left\{\frac{2}{\mu_{r e}-\mu_{s}}\left(F_{A}-C_{r} V_{r s}^{2}\right)\left(e^{\mu_{r e} \beta_{s}}-e^{\mu_{r e} \beta_{0 s}}\right)\right. \\
-\frac{1}{\mu_{s}}\left(e^{\mu_{s} \beta_{s}}-e^{\mu_{s} \beta_{0 s}}\right) \\
\left.\times\left[\frac{\mu_{r e}+\mu_{s}}{\mu_{r e}-\mu_{s}}\left(F_{A}-C_{r} V_{r s}^{2}\right)+E_{A}+C_{e} V_{e s}^{2}\right]\right\},
\end{aligned}
$$

where

$$
C_{s}=\frac{\cos \left(\theta_{s} / 2\right)-\mu_{e p} \cos \gamma \sin \left(\theta_{s} / 2\right)}{2\left(\sin \left(\theta_{s} / 2\right)+\mu_{e p} \cos \gamma \cos \left(\theta_{s} / 2\right)\right)} .
$$

In DBVCVT, the axial clamping force of the primary pulley $Q_{p}$ controls the speed ratio, while the axial clamping force of the secondary pulley $Q_{s}$ controls the slip ratio. It can be imagined that if the clamping force is increased to avoid the slip, the speed ratio must be changed slightly because the speed ratio of DBVCVT depends on the balance of primary and secondary clamping forces. If the primary and secondary clamping forces are in a balance, the speed ratio is constant; if an extra clamping force is applied to either primary or secondary pulleys, DBVCVT will shift. Thus, it is not recommended to decrease the clamping force at one side as this increases the slip in the variator and the influence on DBVCVT would be destabilizing because of the change of speed ratio. As the balance will shift depending on the operating point of DBVCVT, a certain interaction still exists. In the control scheme, the clamping force level in DBVCVT system is controlled by adjusting the spring force.
Overall, this study implements the slip and speed ratio control to minimize the effect of slippage and maintain the speed ratio and improves the transmission efficiency at the same time. It is clear that the working radii of the primary and secondary pulleys in DBVCVT change when the input torque is changed. In other words, the speed ratio changes due to the fact that the axial motions of variators are associated with the slip. This shows that the contribution of change rate of $i$ to the slip $\varepsilon$ cannot be neglected.

A control action is needed in order to stabilize the system in the slip region. In the analytical model and prototype hardware of the DBVCVT, the clamping force of primary pulley $Q_{p}$ and the clamping force of secondary pulley $Q_{s}$ can be controlled. Since the system is mainly used on automotive applications, the input torque $T_{i}$ is controlled by the driver via the throttle pedal, and the output torque $T_{o}$ is determined by the road condition, it can be assumed that the output load is not controllable and hence is considered as the disturbance. For the control purpose, the slip and speed ratio must be measured accurately. In DBVCVT, the geometric ratio $i_{g}$ is obtained from a linear displacement sensor. Since even small offsets in the slip or speed ratio due to temperature changes or elastic deformations may cause severe control errors, all these effects must be taken into account in this control. Therefore, there are disturbances acting on the system.

\section{Slip and Speed Ratio Controller Design}

4.1. Control Scheme. The proposed control scheme is presented in Figure 2. When the input torque is changing, the DBVCVT produces the slip, speed ratio, and transmission efficiency which can also be calculated by using the analytical model. In the prototype DBVCVT, the control signal $Q_{p}$ is transformed to the clamping force of primary pulley and $Q_{s}$ is transformed to the clamping force of secondary pulley via servo motor-driving system. Based on the analytical model of DBVCVT, this paper designs a three-input two-output controller to achieve high transmission efficiency, low belt slip, and accurate speed ratio. For the slip, the controller has to stabilize the system. In short, the controller must be carefully derived. The proposed controller is a fuzzy controller containing 2058 Pareto rules. With the rules, the optimal control action can be easily obtained by mapping 


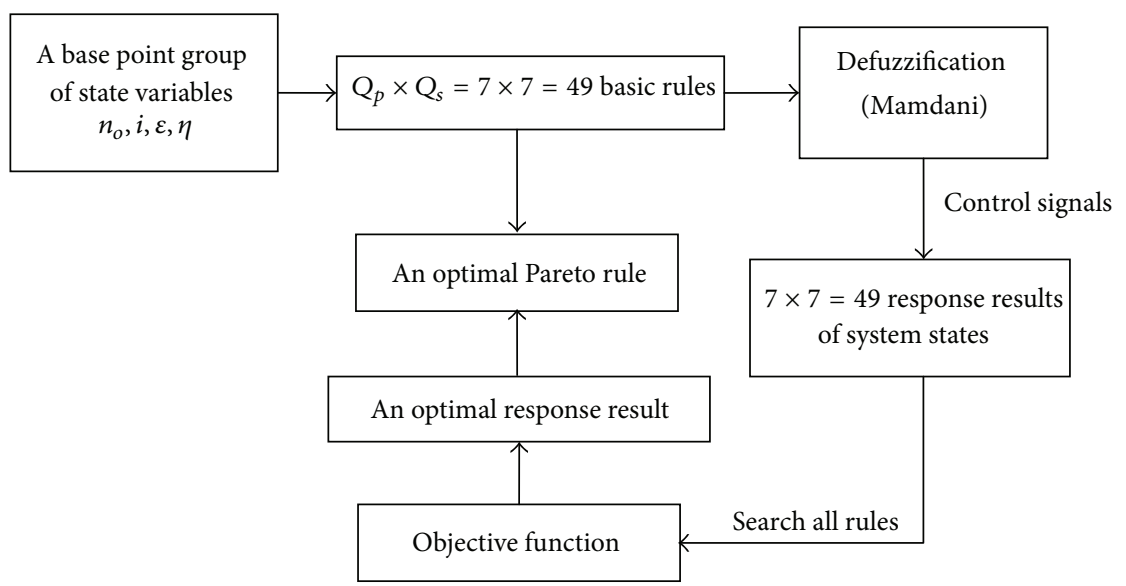

Figure 3: Development of one optimal Pareto rule for DBVCVT.

from the input space to the output space without going through defuzzification [17]. In other words, the response time of the controller can be shortened. The details of the control system are presented in the following sections.

The design of the fuzzy controller is as follows. The input 1 of the controller is defined as the slip $\varepsilon$; its physical dimension is $[0,1.5 \%](i \geq 1)$ or $[0,0.5 \%](i<1)$ [5]. The input 2 of the controller is defined as the speed ratio $i$; its physical dimension is $2 \pm 3 \%(i \geq 1)$ or $0.84 \pm 3 \%(i<1)$ [20]. The input 3 of the controller is defined as the transmission efficiency $\eta$; its physical dimension is $[0,1]$. The output 1 of the controller is the clamping force of primary pulley $Q_{p}$; its physical dimension is [0,20000N]. The output 2 of the controller is the clamping force of secondary pulley $Q_{s}$; its physical dimension is $[0,20000 N]$. The fuzzy domain of these inputs and outputs is $[-6,6]$. The shape of membership function for all three variables is the Gaussian function, in which seven linguistic variables are defined, including negative big "NB," negative medium "NM," negative small "NS," zero "Z," positive small "PS," positive medium "PM," and positive big "PB." The type of fuzzy inference system is Mamdani.

4.2. Establishment of Fuzzy Control Rules. This section describes the establishment of the 2058 optimal control rules which should be accomplished prior to use of the fuzzy controller. To construct the Pareto rule base for DBVCVT, an objective function is necessary. The following section defines some indexes for the objective function.

Definition 7 (error of slip). It defines the error of slip $\varepsilon$ with reference to $\varepsilon_{\text {ref }}$ :

$$
e_{1}=\varepsilon(t)-\varepsilon_{\text {ref }}
$$

Definition 8 (error of speed ratio). It defines the error of speed ratio $i$ with reference to $i_{\text {ref }}$ :

$$
e_{2}=i(t)-i_{\text {ref }}
$$

Definition 9 (error of transmission efficiency). It defines the error of transmission efficiency $\eta$ with reference to $100 \%$ :

$$
e_{3}=100 \%-\eta(t)
$$

Definition 10 (objective function/function of satisfying degree). The above slip and speed ratio control problem can be described as the following objectives:

$$
\begin{aligned}
& \min e_{1}^{2}, \\
& \min e_{2}^{2} \\
& \min e_{3}^{2}
\end{aligned}
$$

Firstly, this research normalizes all targets; the allowable range of variables is mapped to $[0,1]$ by using $(8)$. Then the user gives different weights based on the importance of each target. The objection function of the control system is expressed by

$$
\min f(t)=w_{1} N\left(e_{1}^{2}\right)+w_{2} N\left(e_{2}^{2}\right)+w_{3} N\left(e_{3}^{2}\right)
$$

where $w_{i}(i=1,2,3)$ are user-defined weights for slip control, speed ratio control, and transmission efficiency, respectively. To calculate the errors in the control rule preparation phase, the analytical model of BVCVT is employed, so the above objective function embeds the analytical model.

Besides, the system divides the output speed $n_{o} \in$ $\left[0, n_{o \text { max }}\right]$ into 6 divisions. Generally, $n_{o \text { max }} \leq 6300 \mathrm{RPM}$; these divisions are $[0,1050],[1050,2100],[2100,3150]$, $[3150,4200],[4200,5250]$, and $\left[5250, n_{o \text { max }}\right]$. The three inputs of the fuzzy controller are divided into seven divisions, with respect to seven linguistic values.

In the development of Pareto rule base, it follows the procedure mentioned in Section 2.5. Figure 3 shows the development of one optimal Pareto rule for DBVCVT. On the basis of the division of $n_{o}, n_{o}$ can be calculated as the mean of the current division. In each division of $n_{o}, 7 \times 7=49$ basic rules at the base point group of state variables $\left(n_{o}, i, \varepsilon, \eta\right)$ can be obtained. After defuzzification, $7 \times 7=49$ control 
signals and their corresponding response results of system state can be obtained. Then, with respect to each response result, various system fitness values can be determined by using (53). Based on the minimum fitness, the best Pareto control rule out of 49 for this input condition can be selected. An example rule is shown as follows.

$$
\begin{aligned}
& \text { If } n_{o} \in(1050,2100], \varepsilon \text { is } \mathrm{PS}, i \text { is } \mathrm{NM} \text {, and } \eta \text { is } \mathrm{PM} \text {, then } \\
& Q_{p} \text { is } \mathrm{PM} \text { and } Q_{s} \text { is PM. }
\end{aligned}
$$

In a similar manner, all the rules of various input states can be obtained and a Pareto rule base including $6 \times 7 \times 7 \times 7=$ 2058 optimal Pareto control rules was established. All of these 2058 optimal Pareto rules constitute the fuzzy controller for multiobjective control of DBVCVT.

4.3. Implementation and Experimental Result. In order to verify the feasibility of the proposed algorithm, the above fuzzy controller and the analytical model of DBVCVT were implemented using MATLAB SIMULINK 6.5.1. A prototype DBVCVT with its test rig was also developed as shown in Figure 4. The model parameters are shown in Table 1 in which the geometrical and mechanical parameters come from the manufacturer catalogues, handbooks, and prototype DBVCVT. Besides, the friction coefficients in CVT are known to depend on speed ratio, clamping force, shaft speed, and slip [21]. Under this situation, the previous work [4] considered that the addition of the lubricant can cool and lubricate the system, but an extremely complicated lubricating state exists and varies the friction coefficients in DBVCVT. An oil temperature sensor was employed in the control system to indirectly estimate the friction coefficients. In the previous work [4], by running the DBVCVT for 5 minutes, it was found that the oil temperature remained at about $44^{\circ} \mathrm{C}$ and had no apparent change after several minutes. Thus, based on this temperature, the friction coefficients $\mu_{e p}$ and $\mu_{r e}$ are determined as 0.001 and 0.07 , respectively [19].

In order to examine the control performance of the DBVCVT system under changing input torque, experiment was conducted under two different target speed ratios $\left(i_{\text {ref }}=\right.$ 2 and $\left.i_{\text {ref }}=0.84\right)$. Figures 5 and 11 show the change of input torque for $i_{\text {ref }}=2$ and $i_{\text {ref }}=0.84$, respectively. Figures $5 \sim 16$ and Tables $2 \sim 4$ show the input torque conditions and the experimental results under $i_{\text {ref }}=2$ and $i_{\text {ref }}=$ 0.84 , respectively. All these comparisons not only include the experimental results based on a user-defined weight vector $w=\left(w_{1}, w_{2}, w_{3}\right)^{T}=(0.3,0.5,0.2)^{T}$ (Condition 1) but also include the results based on another set of user-defined weights $w=\left(w_{1}, w_{2}, w_{3}\right)^{T}=(0.5,0.3,0.2)^{T}$ (Condition 2). The reason for testing the system under two different weight combinations is to reflect the impact of weights on system performance. As mentioned before, the slip control and speed ratio control is a pair of conflicting goals. This paper pays more attention on the speed ratio control in Condition 1 and pays more attention on the slip control in Condition 2. The comparison of Condition 1 and Condition 2 in Figures 5 16 proves that the weight has a great influence on the control rules in the Pareto rule base and control performance.

As for the speed ratio of DBVCVT, Table 2, Figures 6 and 12 show the comparison of experimental conditions and

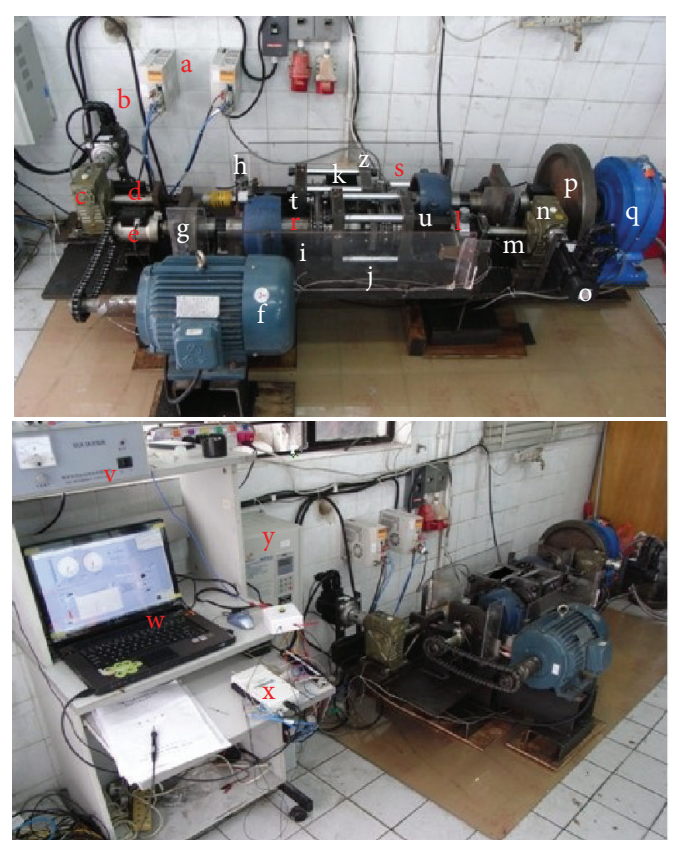

FIgURE 4: Experimental setup of prototype DBVCVT and test rig. (a) DC servo motor controllers; (b) DC servo motor (secondary pulleys); (c) worm gearbox of DC servo motor (secondary pulleys); (d) power screw mechanism (secondary pulleys); (e) integral torque and speed sensors (primary pulleys); (f) three-phase AC motor; (g) spring; (h) load cell (secondary pulleys); (i) variator 1 ; (j) variator 2 ; (k) inverse differential gearbox; (l) load cell (primary pulleys); (m) power screw mechanism (primary pulleys); (n) worm gearbox of DC servo motor (primary pulleys); (o) DC servo motor (primary pulleys); (p) flywheel; (q) magnetic powder dynamometer; (r) input shaft; (s) output shaft; (t) synchronous shift fork (secondary pulleys); (u) synchronous shift fork (primary pulleys); (v) dynamometer controller; (w) control program; (x) programmable ECU; (y) inverter for AC motor; (z) optical sensor.

experimental results of speed ratio in DBVCVT system under $i_{\text {ref }}=2$ and $i_{\text {ref }}=0.84$, respectively. In Figures 6 and 12, it can be noted that though the input torque is changing, the actual speed ratio can follow the $i_{\text {ref }}$ quickly and accurately. From Table 2, it can be found that no matter the target speed ratio is 2 or 0.84 , all the errors between $i_{\text {ref }}$ and the maximum of $i$ in Condition 1 are less than those in Condition 2. Similarly, all the errors between $i_{\text {ref }}$ and the minimum of $i$ in Condition 1 are less than those in Condition 2. In all, all the errors are in the limitation of $[-3 \%,+3 \%][20]$, which show that the control performance of the speed ratio is very good. Moreover, the curves of Condition 1 in Figures 6 and 12 are better than those of Condition 2 in Figures 6 and 12. It is because the weight of speed ratio in Condition 1 is larger than the one in Condition 2.

As for the slip ratio of DBVCVT, Table 3, Figures 7 and 13 show the comparison of experimental conditions and experimental results of belt slip in DBVCVT system under $i_{\text {ref }}=2$ and $i_{\text {ref }}=0.84$, respectively. In Figures 7 and 13, it can be seen that though the input torque is changing, the slip ratio is almost controlled under the limitation of $\varepsilon_{\text {ref }}=$ $1.5 \%(i \geq 1)$ or $0.5 \%(i<1)$ [5]. From Table 3, even the 
TABLE 1: Parameters of analytical model and prototype of DBVCVT.

\begin{tabular}{lcccccc}
\hline$a$ & $C_{e}$ & $C_{r}$ & $d_{b}$ & $\varepsilon_{\text {ref }}$ & $f_{b}$ & $h$ \\
\hline $195 \mathrm{~mm}$ & $2 \mathrm{~kg} / \mathrm{m}$ & $0.04 \mathrm{~kg} / \mathrm{m}$ & $70 \mathrm{~mm}$ & $\begin{array}{c}1.5 \%(i \geq 1) \\
0.5 \%(i<1)\end{array}$ & 0.7 & $2 \mathrm{~mm}$ \\
\hline$h_{r}$ & $i_{\text {ref }}$ & $K$ & $L$ & $m_{e}$ & $N_{r}$ & $v_{b}$ \\
\hline $0.185 \mathrm{~mm}$ & $\begin{array}{c}2(i \geq 1) \\
0.84(i<1)\end{array}$ & $5.5 \mathrm{~mm}$ & $598 \mathrm{~mm}$ & $0.005 \mathrm{~kg}$ & 12 & $40 \mathrm{~mm}^{2} / \mathrm{s}$ \\
\hline$\eta_{d}$ & $\eta_{d t}$ & $\theta_{p}$ & $\theta_{s}$ & $\mu_{e p}$ & $\mu_{r e}$ & \\
\hline 0.9 & 0.95 & $11^{\circ}$ & $11^{\circ}$ & 0.001 & 0.07 & \\
\hline
\end{tabular}

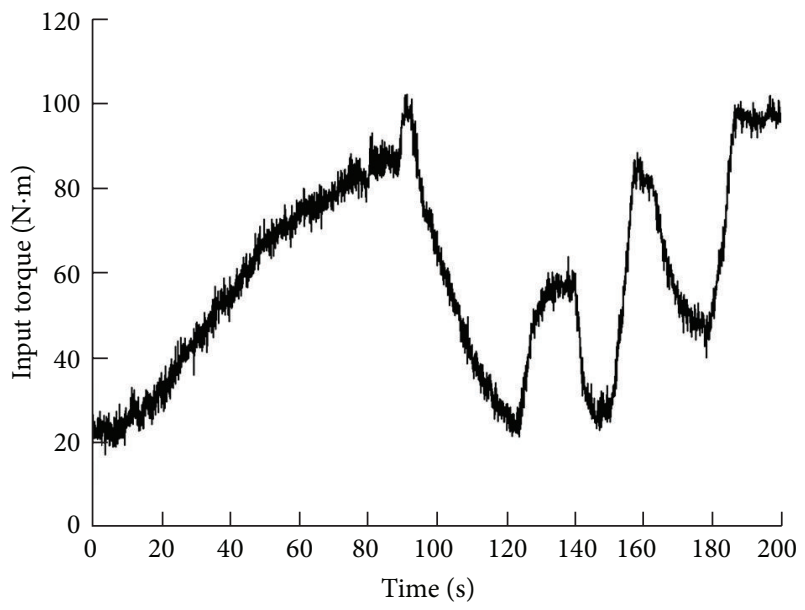

FIGURE 5: Input torque in DBVCVT system for $i_{\text {ref }}=2$.

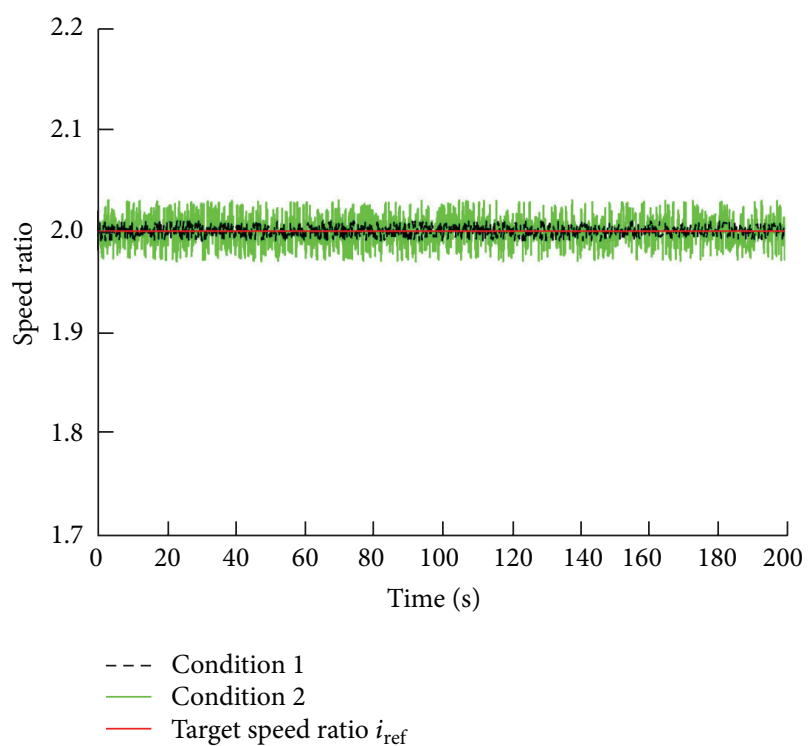

FIGURE 6: Time response of speed ratio in DBVCVT system for $i_{\text {ref }}=$ 2 .

maximum overshoot of slip ratio $\varepsilon$ excesses $\varepsilon_{\text {ref; }}$; the clamping forces $Q_{p}$ and $Q_{s}$ keep adjusting to gradually decrease the slip. Besides, it can be noticed that no matter the target speed ratio is 2 or 0.84 , all the means of actual slip ratio $\varepsilon_{\text {mean }}$ are under

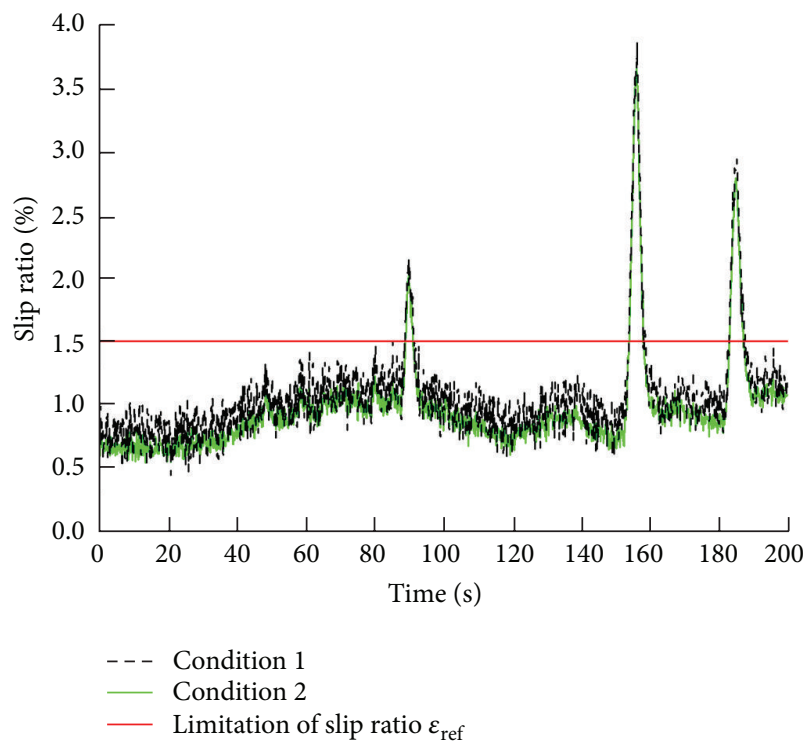

FIgURE 7: Time response of slip ratio in DBVCVT system for $i_{\text {ref }}=2$.

the limitation of $\varepsilon_{\text {ref }}=1.5 \%(i \geq 1)$ or $0.5 \%(i<1)$, showing that the control performance of the slip ratio is very good. Furthermore, Table 3 reveals that all the errors of Condition 1 are larger than those of Condition 2, in which it can also be seen that the curves of Condition 1 in Figures 7 and 13 are worse than those of Condition 2 in Figures 7 and 13. It is because the weight of slip ratio in Condition 1 is less than the one in Condition 2.

As for the transmission efficiency of DBVCVT, Table 4, Figures 8 and 14 show the experimental results of transmission efficiency in DBVCVT system under $i_{\text {ref }}=2$ and $i_{\text {ref }}=0.84$, respectively. In Figures 8 and 14, it can be seen that though the input torque is changing, the transmission efficiency can be maintained or even improved by the multiobjective fuzzy controller. When the slip ratio specially excesses $\varepsilon_{\text {ref }}$ at $t=87 \mathrm{~s}, 158 \mathrm{~s}$, or $190 \mathrm{~s}$ in Figure 7 , the corresponding transmission efficiency at $t=87 \mathrm{~s}, 158 \mathrm{~s}$, or $190 \mathrm{~s}$ in Figure 8 does not drop down seriously. Similarly, when the slip ratio excesses $\varepsilon_{\text {ref }}$ at $t=63 \mathrm{~s}, 155 \mathrm{~s}, 165 \mathrm{~s}$, or $196 \mathrm{~s}$ in Figure 13, the corresponding transmission efficiency at $t=63 \mathrm{~s}, 155 \mathrm{~s}, 165 \mathrm{~s}$, or $196 \mathrm{~s}$ in Figure 14 still does not drop down significantly. It is because that the transmission efficiency at high slip level is maintained by balancing the clamping forces $Q_{p}$ and $Q_{s}$. From Table 4 , it can be found 


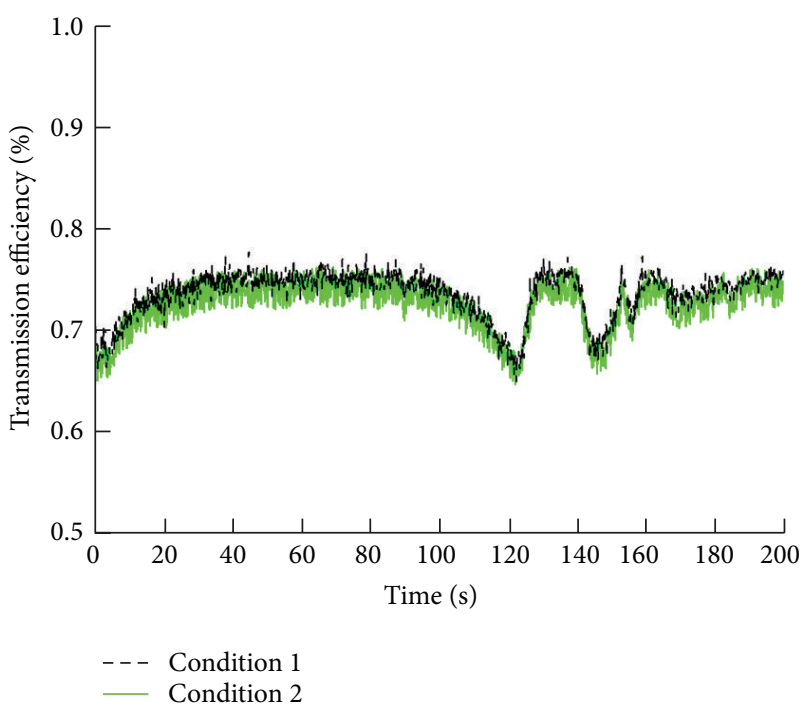

FIGURE 8: Time response of transmission efficiency in DBVCVT system for $i_{\text {ref }}=2$.

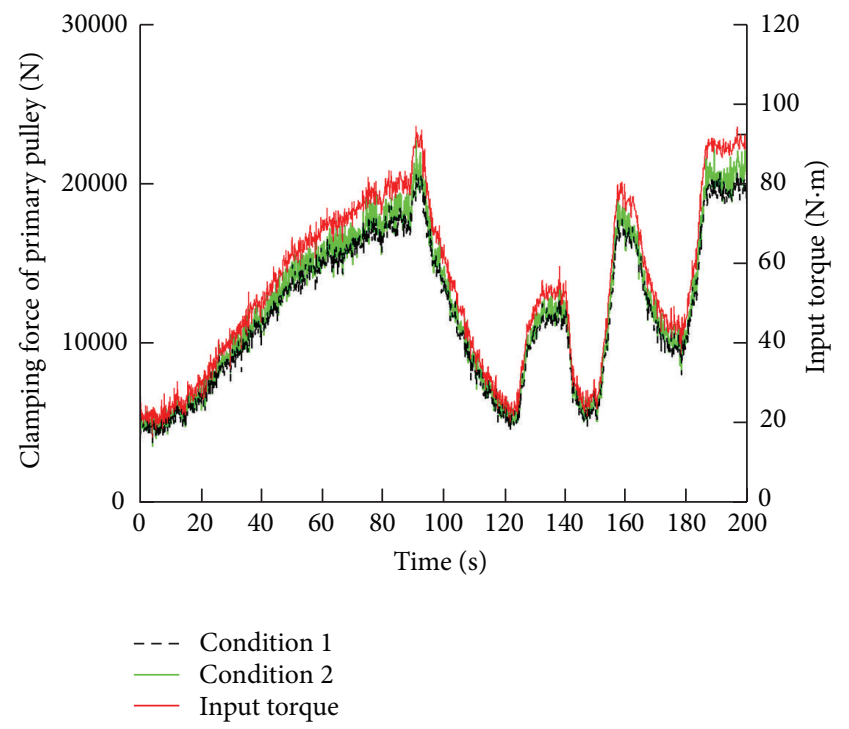

FIGURE 9: Time response of clamping force of primary pulley in DBVCVT system for $i_{\text {ref }}=2$.

that no matter the target speed ratio is 2 or 0.84 , all the errors between 1 (i.e., $100 \%$ efficiency) and the means of actual transmission efficiency $\eta_{\text {mean }}$ are acceptable, because the power transmission efficiency of a general CVT is about $70 \%$. Furthermore, the curves of Condition 2 in Figures 8 and 14 are slightly worse than those of Condition 1 . These results reveal that although the weight of transmission efficiency in Condition 1 is the same as the one in Condition 2, increasing the weight of slip control in Condition 2 slightly increases the friction loss, resulting in decreasing the transmission efficiency a little. This evidence proves that the proposed control strategy can meet different conflicting targets in a sense of compromise.

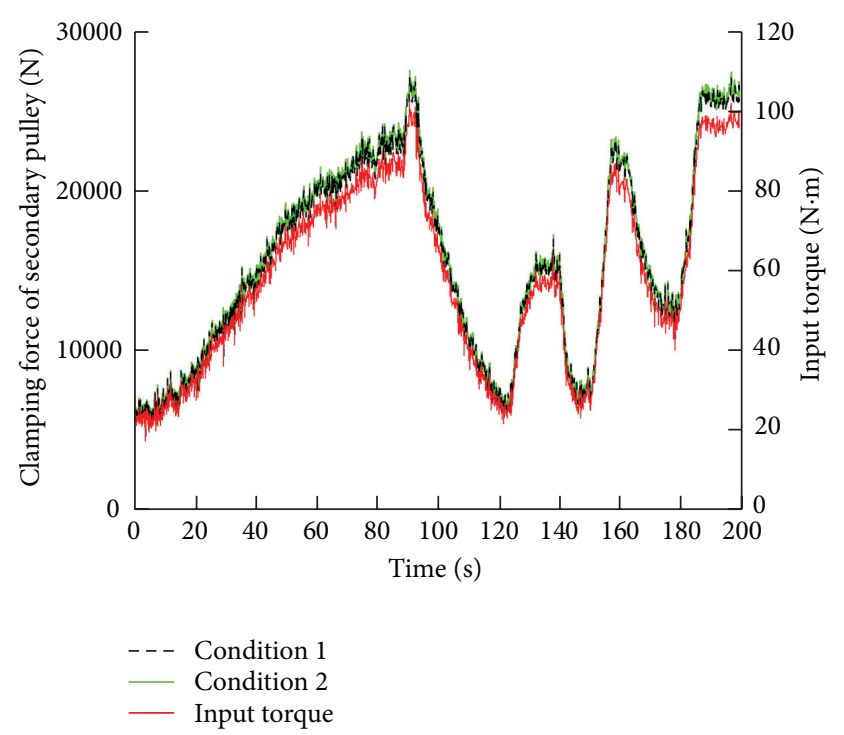

FIGURE 10: Time response of clamping force of secondary pulley in DBVCVT system for $i_{\text {ref }}=2$.

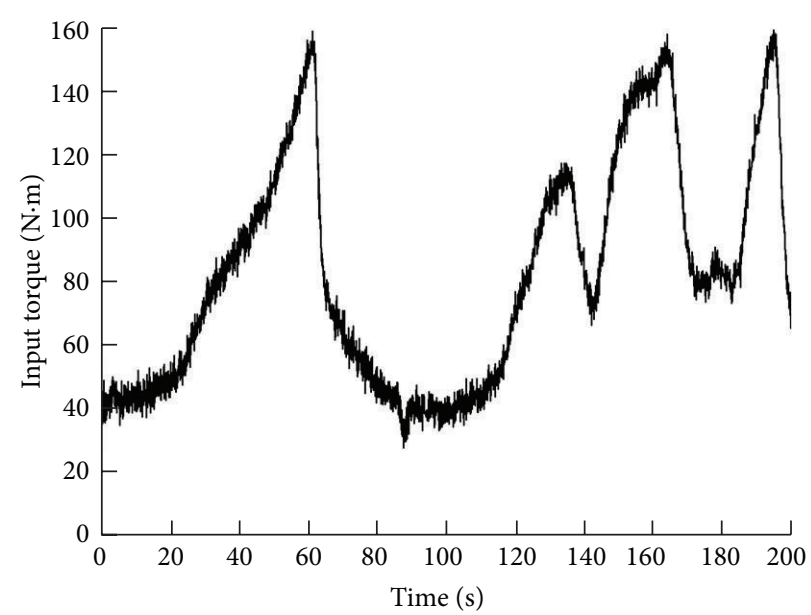

FIGURE 11: Input torque in DBVCVT system for $i_{\text {ref }}=0.84$.

In addition, Figures 9, 10, 15, and 16 illustrate that the clamping forces of $Q_{p}$ and $Q_{s}$ have a good agreement with the input torque in Figures 5 and 11, respectively, showing that the proposed fuzzy controller has a good tracking performance and fast response time. In all, the proposed fuzzy controller can improve the transmission efficiency, achieve the accurate speed ratio, and avoid the slip in the highly nonlinear DBVCVT system.

\section{Conclusions}

Considering that there is very little research on the simultaneous control of slip, speed ratio, and transmission efficiency of metallic V-belt CVTs, this paper originally proposes a multiobjective control strategy for the CVT system. As a novel DBVCVT system has been previously proposed by the 


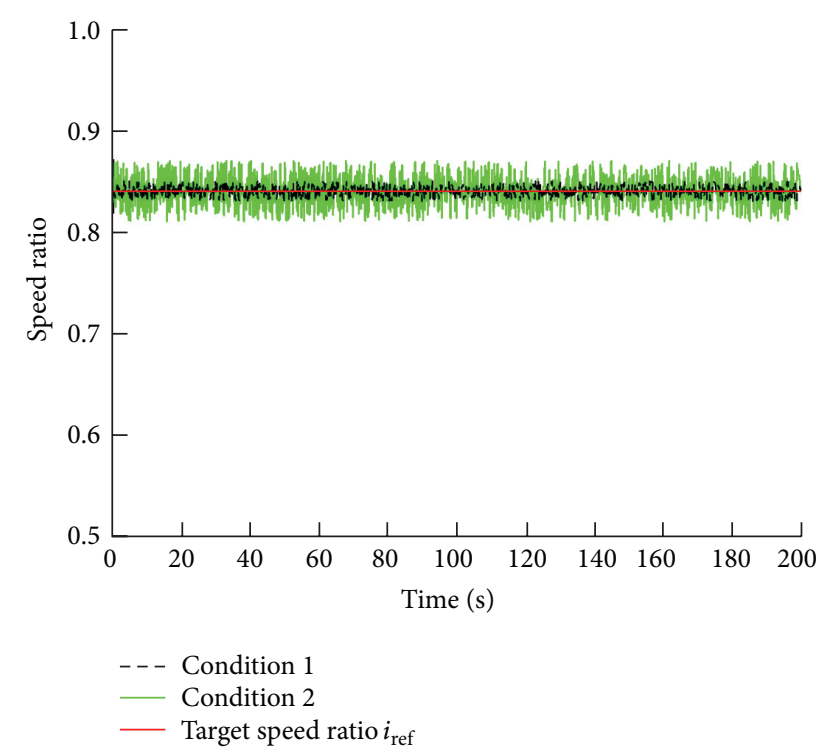

FIGURE 12: Time response of speed ratio in DBVCVT system for $i_{\text {ref }}=0.84$.

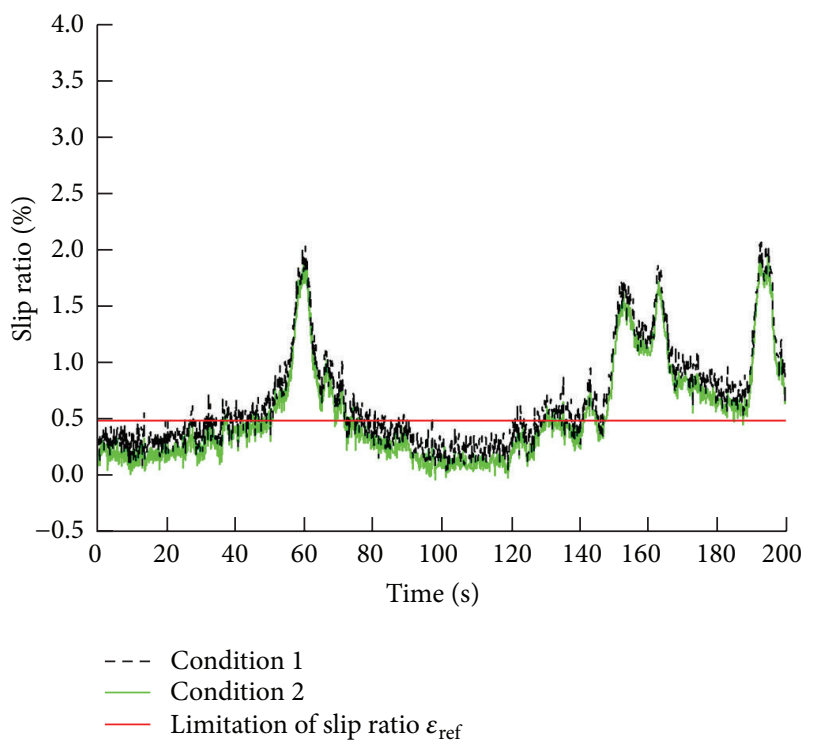

FIGURE 13: Time response of slip ratio in DBVCVT system for $i_{\text {ref }}=$ 0.84 .

authors, a new intelligent controller under the multicontrol strategy is then designed to improve the DBVCVT performance in terms of transmission reliability, efficiency, and stability. Due to the high nonlinearity of DBVCVT, the fuzzy control theory is adopted. While the rule base is critical for the fuzzy control algorithm, this paper not only originally applies Pareto strategy to generate optimal control rules for DBVCVT but also defines a comprehensive and flexible objective function to help with generating the optimal control rules.

To verify the control strategy, a prototype system was implemented using MATLAB in which the output speed is

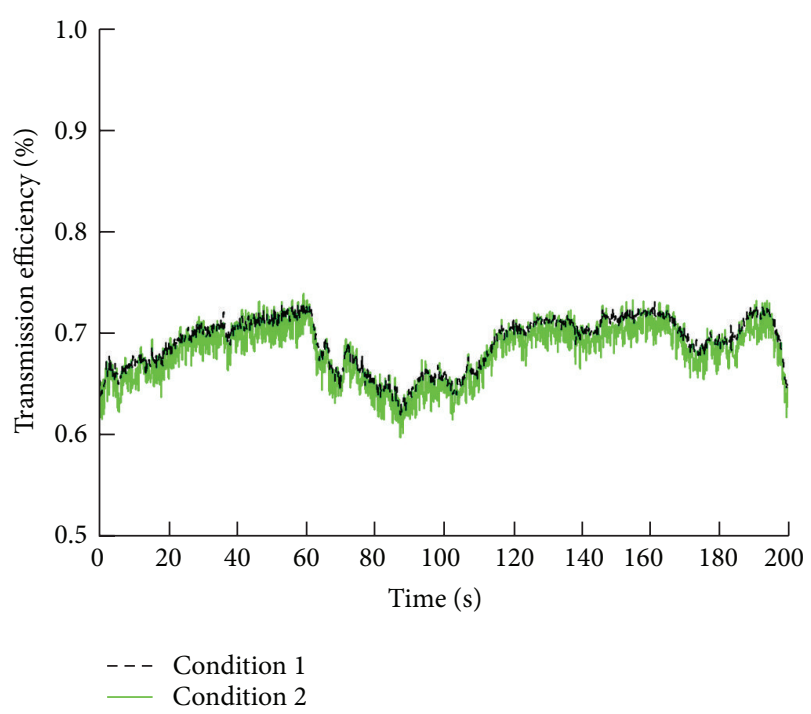

FIGURE 14: Time response of transmission efficiency in DBVCVT system for $i_{\text {ref }}=0.84$.

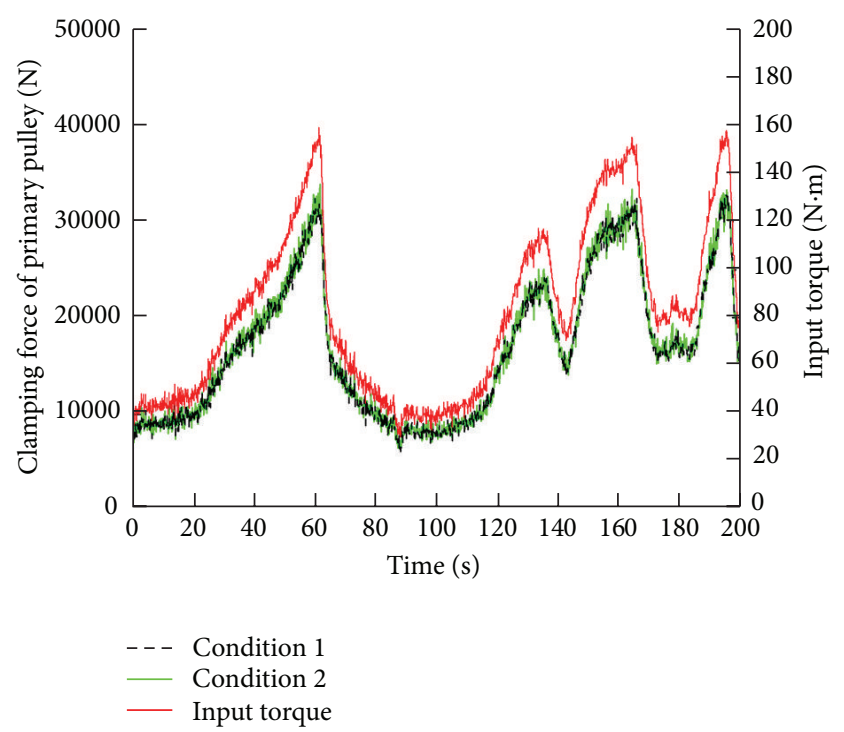

FIGURE 15: Time response of clamping force of primary pulley in DBVCVT system for $i_{\text {ref }}=0.84$.

separated into six divisions. With the help of the relevant membership function, the proposed system can derive optimal fuzzy control rules. Experimental results not only verify that the multiobjective fuzzy control strategy for DBVCVT can balance the goals of accurate speed ratio and low belt slip but also show that the controller can achieve a good transmission performance. In addition, this paper further demonstrates the effectiveness of the proposed method by using different weight vectors. In short, the use of the fuzzy control algorithm based on Pareto rule base for the multiobjective control problem of DBVCVT is effective.

In the future, the test condition of continuous shift point commands will be considered to further examine the 


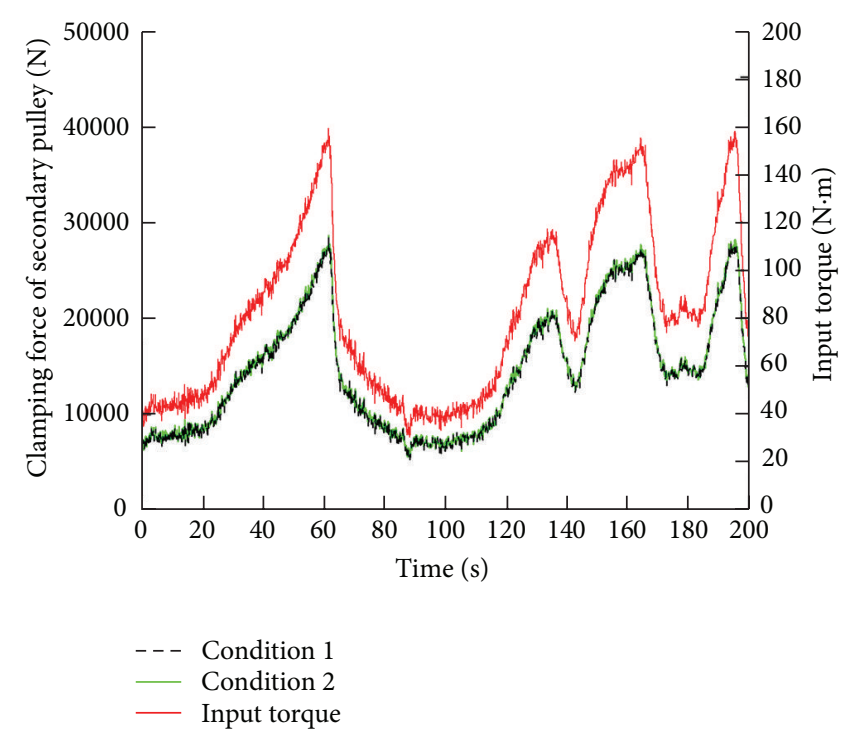

FIGURE 16: Time response of clamping force of secondary pulley in DBVCVT system for $i_{\text {ref }}=0.84$.

TABLE 2: Comparison of results of speed ratio in Conditions 1 and 2.

\begin{tabular}{|c|c|c|c|c|}
\hline Target speed ratio $i_{\text {ref }}$ & Maximum of actual speed ratio $i$ & $\begin{array}{c}\text { Error } \\
(\%)\end{array}$ & Minimum of actual speed ratio $i$ & $\begin{array}{c}\text { Error } \\
(\%)\end{array}$ \\
\hline \multirow{2}{*}{2} & 2.015 (Condition 1) & $1.5 \%$ & 1.983 (Condition 1) & $-1.7 \%$ \\
\hline & 2.029 (Condition 2) & $2.9 \%$ & 1.975 (Condition 2) & $-2.5 \%$ \\
\hline \multirow{2}{*}{0.84} & 0.848 (Condition 1$)$ & $0.8 \%$ & 0.835 (Condition 1$)$ & $-0.5 \%$ \\
\hline & $0.872($ Condition 2$)$ & $3.2 \%$ & $0.813($ Condition 2$)$ & $-2.7 \%$ \\
\hline
\end{tabular}

TABLE 3: Comparison of results of slip ratio in Conditions 1 and 2.

\begin{tabular}{|c|c|c|c|c|}
\hline $\begin{array}{l}\text { Target speed } \\
\text { ratio } i_{\text {ref }}\end{array}$ & $\begin{array}{l}\text { Limitation of slip } \\
\text { ratio } \varepsilon_{\text {ref }}\end{array}$ & $\begin{array}{l}\text { Maximum of overshoot } \\
\text { of slip ratio } \varepsilon\end{array}$ & $\begin{array}{l}\text { Mean of actual slip } \\
\quad \text { ratio } \varepsilon_{\text {mean }}\end{array}$ & $\begin{array}{c}\text { Error } \\
\left(\varepsilon_{\text {mean }}-\varepsilon_{\text {ref }}\right) \\
(\%)\end{array}$ \\
\hline \multirow[b]{2}{*}{2} & \multirow{2}{*}{$1.5 \%$} & $\begin{array}{c}3.870 \% \\
\text { (Condition 1) }\end{array}$ & $\begin{array}{c}1.038 \% \\
\text { (Condition } 1)\end{array}$ & $-0.462 \%$ \\
\hline & & $\begin{array}{c}3.662 \% \\
\text { (Condition 2) }\end{array}$ & $\begin{array}{c}0.947 \% \\
(\text { Condition 2) } \\
\end{array}$ & $-0.553 \%$ \\
\hline \multirow[b]{2}{*}{0.84} & \multirow{2}{*}{$0.5 \%$} & $\begin{array}{c}2.127 \% \\
\text { (Condition 1) }\end{array}$ & $\begin{array}{c}0.488 \% \\
\text { (Condition 1) }\end{array}$ & $-0.012 \%$ \\
\hline & & $\begin{array}{c}1.978 \% \\
\text { (Condition 2) }\end{array}$ & $\begin{array}{c}0.463 \% \\
\text { (Condition 2) }\end{array}$ & $-0.037 \%$ \\
\hline
\end{tabular}

TABLE 4: Comparison of results of transmission efficiency in Conditions 1 and 2.

\begin{tabular}{lccr}
\hline $\begin{array}{l}\text { Target speed } \\
\text { ratio } i_{\text {ref }}\end{array}$ & $\begin{array}{c}\text { Target } \\
\text { transmission } \\
\text { efficiency }\end{array}$ & $\begin{array}{c}\text { Mean of actual } \\
\text { transmission } \\
\text { efficiency } \eta_{\text {mean }}\end{array}$ & $\begin{array}{c}\text { Error } \\
(\%)\end{array}$ \\
\hline 2 & & $73.72 \%$ (Condition 1) & $26.28 \%$ \\
& & $72.16 \%$ (Condition 2) & $27.84 \%$ \\
0.84 & 1 & $69.32 \%$ (Condition 1) & $30.68 \%$ \\
\hline
\end{tabular}


performance of the proposed controller. Although the above case study shows a good control performance, additional tests under more complicated conditions are also necessary to be considered, like the variable output load.

\section{Nomenclature}

$e_{1}$ :

$e_{2}$ :

$e_{3}:$

$F_{\text {spring }}$ :

$F_{t p}=F_{t p}(\beta)$

pulley

$F_{t s}=F_{t s}(\beta)$ : Distribution of tangential friction between steel element and secondary pulley

$h:$ Radial distance from contact surface between steel ring and steel element to center of gravity of steel element

$h_{e}: \quad$ Thickness of each steel element

$h_{r}$ : Thickness of each layer in steel ring

$i$ : Transmission ratio

$i_{g}: \quad$ Geometric ratio

$i_{\text {max }}$ :

$i_{\text {min }}$ :

$i_{\text {ref: }}:$

Maximum transmission ratio

Minimum transmission ratio

Reference of speed ratio

$K$ : $\quad$ Experimental constant of effective radius

$k_{p}:$

Effective radius coefficient of

primary pulley

$k_{s}$ : $\quad$ Effective radius coefficient of secondary pulley

$L$ : $\quad$ Working length of steel belt

$m_{e}$ : $\quad$ Mass of each steel element

$n: \quad$ Number of metal belts

$n_{i}: \quad$ Input speed

$n_{o}: \quad$ Output speed

$n_{o 1}$ : $\quad$ Output speed of secondary pulley 1

$n_{o 2}$ : $\quad$ Output speed of secondary pulley 2

$n_{\text {o max }}$ : $\quad$ Maximum of output speed

$N_{p}=N_{p}(\beta)$ : Distribution of normal force between steel element and primary pulley

$N_{r}$ : $\quad$ Number of layers in steel ring

$N_{s}=N_{s}(\beta)$ : Distribution of normal force between steel element and secondary pulley

$P_{1}$ : $\quad$ Power loss due to radial friction between steel element and pulley

$P_{2}$ : $\quad$ Power loss due to tangential friction between steel element and pulley

$P_{3}$ : $\quad$ Power loss due to friction between inner layer of steel ring and contact surface of steel element $P_{4}: \quad$ Kinetic energy loss of steel element
$P_{5}$ : $\quad$ Power loss due to speed-dependent bearing frictional torque of input shaft

$P_{6}$ : $\quad$ Power loss due to speed-dependent bearing frictional torque of output shaft

$P_{\text {loss: }}: \quad$ Slip loss

$P_{p}=P_{p}(\beta)$ : Distribution of normal force between steel ring and steel element on primary pulley

$P_{s}=P_{s}(\beta): \quad$ Distribution of normal force between steel ring and steel element on secondary pulley

$Q_{p}=Q_{p}(\beta)$ : Distribution of axial clamping force of primary pulley

$Q_{s}=Q_{s}(\beta)$ : Distribution of axial clamping force of secondary pulley

$r_{p}: \quad$ Working radius of primary pulley

$r_{p i}$ : $\quad$ Effective radius at the entry of primary pulley

$r_{p o}$ : $\quad$ Effective radius at the exit of primary pulley

$r_{s}$ : Working radius of secondary pulley

$r_{s i}$ : $\quad$ Effective radius at the entry of secondary pulley

$r_{s o}$ : $\quad$ Effective radius at the exit of secondary pulley

$t: \quad$ Time

$T_{i}: \quad$ Input torque

$v_{b}: \quad$ Kinematic viscosity of lubricant

$V_{e}: \quad$ Tangential velocity of steel element based on effective radius

$V_{e p}: \quad$ Tangential velocity of steel element on primary pulley

$V_{e s}: \quad$ Tangential velocity of steel element on secondary pulley

$v_{p}: \quad$ Tangential velocity of primary pulley

$V_{r p}$ : Tangential velocity of steel ring on primary pulley

$V_{r s}: \quad$ Tangential velocity of steel ring on secondary pulley

$v_{s}$ : Tangential velocity of secondary pulley

$w$ : User-defined weight

$\alpha: \quad$ Angle between the vertical centerline of shaft and the tangent point of steel belt

$\beta_{0 p}: \quad$ Angle of increase or decrease in $E_{p}$

$\beta_{0 s}: \quad$ Angle of increase or decrease in $E_{s}$

$\beta_{p}$ : $\quad$ Angle of wrap of a belt on primary pulley

$\beta_{s}$ : $\quad$ Angle of wrap of a belt on secondary pulley

$\gamma: \quad$ Sliding angle

$\Delta r_{p}: \quad$ Measured axial moving displacement of primary pulley

$\Delta r_{p \text {, max }}: \quad$ Measured maximum of axial moving displacement of primary pulley

$\varepsilon: \quad$ Slip ratio

$\varepsilon_{\text {mean }}: \quad$ Mean of actual slip ratio

$\varepsilon_{\text {ref }}: \quad$ Reference of slip ratio

$\zeta: \quad$ Disturbance

$\eta$ : $\quad$ Power transmission efficiency

$\eta_{d}: \quad$ Transmission efficiency of inverse differential gear

$\eta_{\text {mean }}: \quad$ Mean of actual transmission efficiency

$\theta_{p}: \quad$ Groove angle of primary pulley 
$\theta_{s}:$ Groove angle of secondary pulley

$\lambda$ : Compromising operator

$\mu_{e p}$ : Friction coefficient between steel element and pulley

$\mu_{r e}$ : Friction coefficient between steel ring and steel element

$\tau$ : Sampling period

$\omega_{p}$ : Angular velocity of primary pulley

$\omega_{s}$ : Angular velocity of secondary pulley.

\section{Conflict of Interests}

The authors declare that there is no conflict of interests regarding the publication of this paper.

\section{Acknowledgment}

The project is supported by the University of Macau Research Grants, Grant nos. MYRG2014-00058-FST, MYRG081(Y1L2)-FST12-WPK, and MYRG077(Y1-L2)-FST13-WPK.

\section{References}

[1] W. Ryu, J. Nam, Y. Lee, and H. Kim, "Model based control for a pressure control type CVT," International Journal of Vehicle Design, vol. 39, no. 3, pp. 175-188, 2005.

[2] S. Simons, Shift dynamics modelling for optimization of variator slip control in a continuously variable transmission [M.S. thesis], Eindhoven University of Technology, 2006.

[3] Y. Zhou, J. Liu, Y. Cai, and N. Zou, "Modeling, validation and optimal design of the clamping force control valve used in continuously variable transmission," Chinese Journal of Mechanical Engineering, vol. 21, no. 4, pp. 51-55, 2008.

[4] Y. Q. Chen, P. K. Wong, Z. C. Xie, H. W. Wu, K. U. Chan, and J. L. Huang, "Modelling of a novel dual-belt continuously variable transmission for automobiles," World Academy of Science Engineering and Technology, no. 70, pp. 1157-1161, 2012.

[5] B. Bonsen, T. W. G. L. Klaassen, R. J. Pulles, S. W. H. Simons, M. Steinbuch, and P. A. Veenhuizen, "Performance optimisation of the push-belt CVT by variator slip control," International Journal of Vehicle Design, vol. 39, no. 3, pp. 232-256, 2005.

[6] B. Bonsen, R. J. Pulles, S. W. H. Simons, M. Steinbuch, and P. Veenhuizen, "Implementation of a slip controlled CVT in a production vehicle," in Proceedings of IEEE Conference on Control Applications (CCA '05), pp. 1212-1217, Toronto, Canada, August 2005.

[7] T. Saito and A. D. Lewis, "Development of a simulation technique for CVT metal pushing V-belt with feedback control," SAE Transactions, vol. 113, no. 6, pp. 926-932, 2004.

[8] P. Setlur, J. R. Wagner, D. M. Dawson, and B. Samuels, "Nonlinear control of a continuously variable transmission (CVT)," IEEE Transactions on Control Systems Technology, vol. 11, no. 1, pp. 101-108, 2003.

[9] T. Kim, H. Kim, J. Yi, and H. Cho, "Ratio control of metal belt CVT," SAE Paper No. 2000-01-0842, 2000.

[10] M. Pesgens, B. Vroemen, B. Stouten, F. Veldpaus, and M. Steinbuch, "Control of a hydraulically actuated continuously variable transmission," Vehicle System Dynamics, vol. 44, no. 5, pp. 387-406, 2006.
[11] Y. Rothenbühler, New slip synthesis and theoretical approach of CVT slip control [Ph.D. thesis], Ecole Polytechnique Federale de Lausanne, 2009.

[12] S. P. Zhang, The research on coupling of push V-belt continuously variable transmission [Ph.D. thesis], Jilin University, 2011.

[13] T. Takiyama, "Engine-CVT-A/F consolidated control using decoupling control theory," JSAE Review, vol. 22, no. 1, pp. 914, 2001.

[14] G. Chen and T. T. Pham, Introduction to Fuzzy Sets, Fuzzy Logic, and Fuzzy Control Systems, Taylor \& Francis, 2000.

[15] K. S. Tang, K. F. Man, G. Chen, and S. Kwong, "An optimal fuzzy PID controller," IEEE Transactions on Industrial Electronics, vol. 48, no. 4, pp. 757-765, 2001.

[16] C. Chang, D. Xu, and H. Quek, "Pareto-optimal set based multiobjective tuning of fuzzy automatic train operation for mass transit system," IEE Proceedings-Electric Power Applications, vol. 146, no. 5, pp. 577-583, 1999.

[17] R. R. Yager and L. A. Zadeh, An Introduction to Fuzzy Logic Applications in Intelligent Systems, Springer, 2012.

[18] H. Ishibuchi, I. Kuwajima, and Y. Nojima, "Relation between pareto-optimal fuzzy rules and pareto-optimal fuzzy rule sets," in Proceedings of the 1st IEEE Symposium of Computational Intelligence in Multicriteria Decision Making (MCDM '07), pp. 42-49, April 2007.

[19] R. Budynas and K. Nisbett, Shigley's Mechanical Engineering Design, SI units, McGraw-Hill, New York, NY, USA, 9th edition, 2011.

[20] G. Carbone, L. Mangialardi, and G. Mantriota, "Theoretical model of metal V-belt drives during rapid ratio changing," Journal of Mechanical Design, vol. 123, no. 1, pp. 111-117, 2001.

[21] B. G. Vroemen, Component control for the zero inertia powertrain [Ph.D. thesis], Eindhoven University of Technology, 2001. 


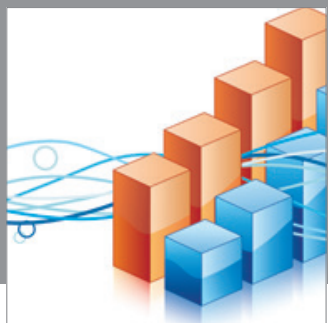

Advances in

Operations Research

mansans

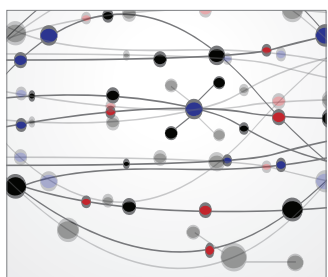

The Scientific World Journal
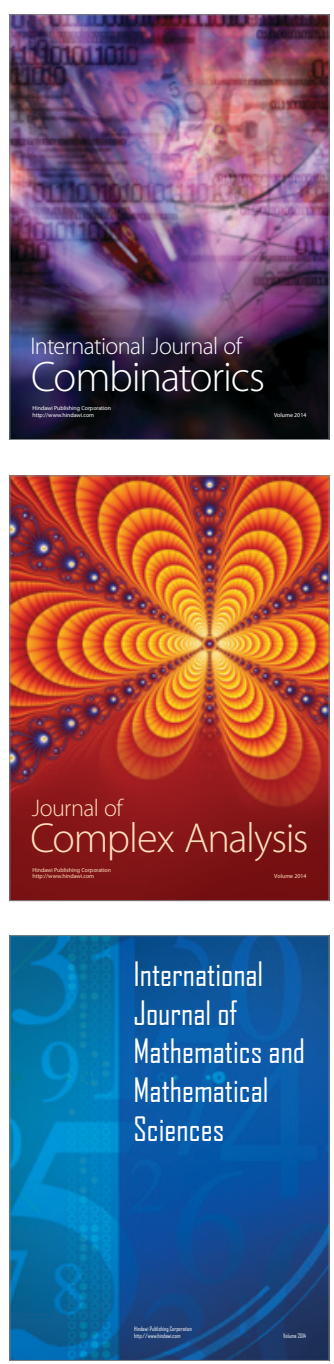
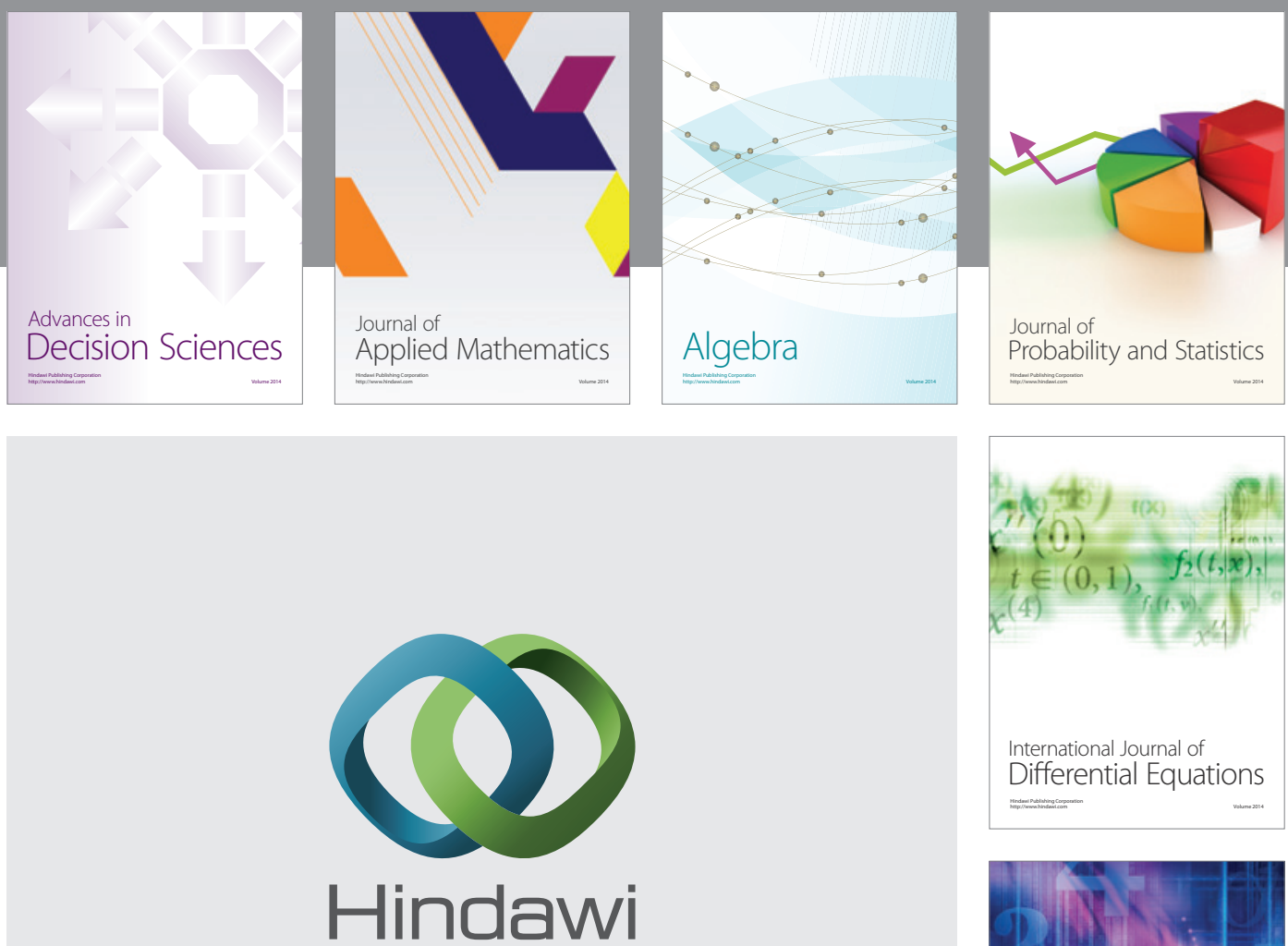

Submit your manuscripts at http://www.hindawi.com
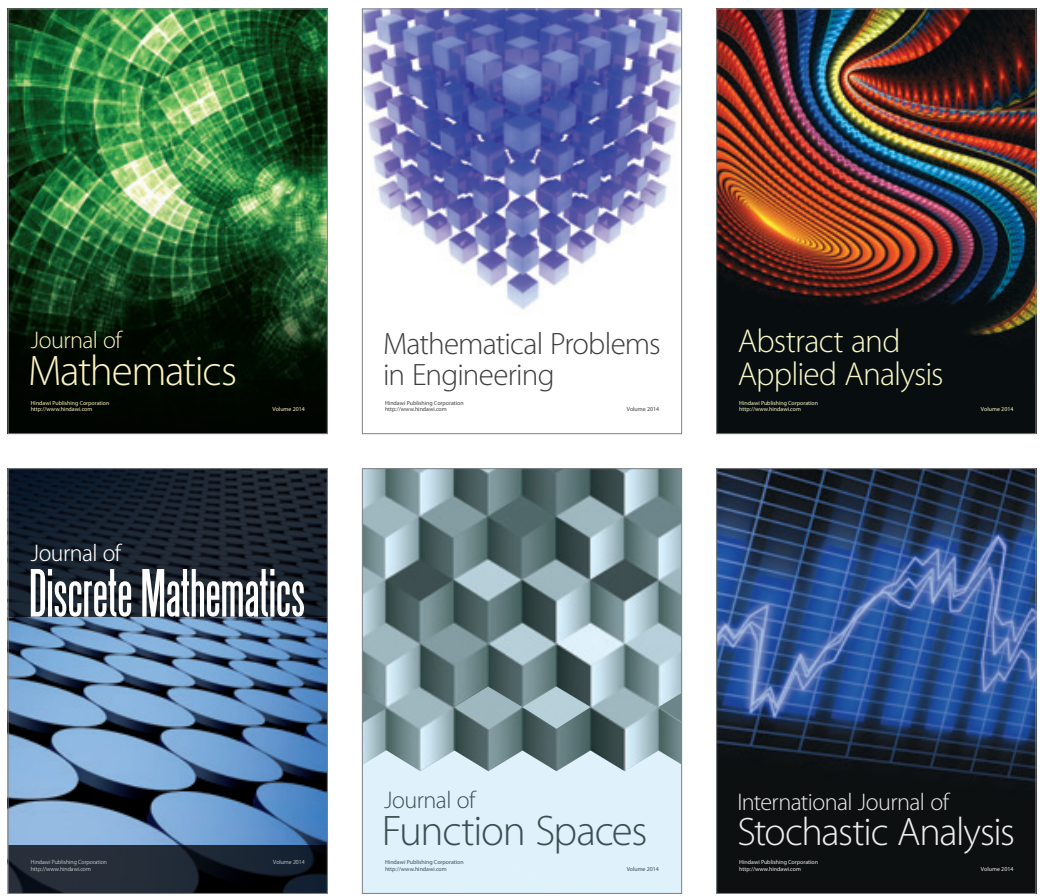

Journal of

Function Spaces

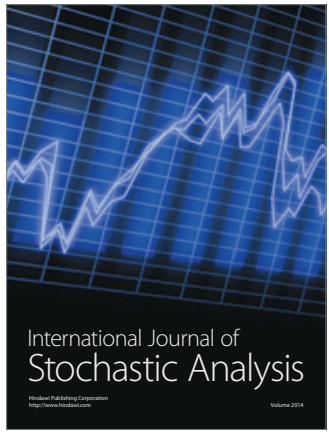

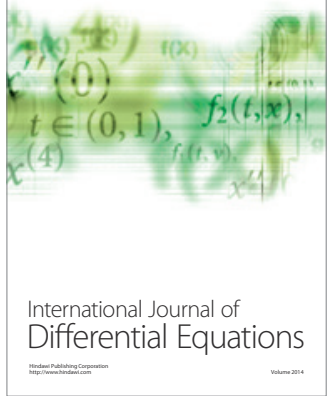
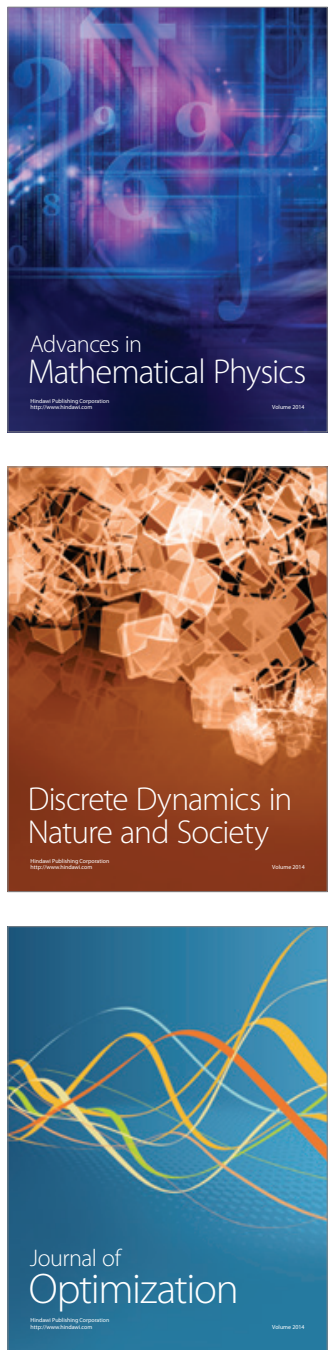